\title{
Tidally Driven Processes Leading to Near-Field Turbulence in a Channel at the Crest of the Mendocino Escarpment*
}

\author{
R. C. Musgrave, ${ }^{+}$J. A. MacKinnon, R. Pinkel, and A. F. Waterhouse \\ Scripps Institution of Oceanography, University of California, San Diego, La Jolla, California
}

J. NASH

Oregon State University, Corvallis, Oregon

(Manuscript received 30 January 2015, in final form 11 January 2016)

\begin{abstract}
In situ observations of tidally driven turbulence were obtained in a small channel that transects the crest of the Mendocino Ridge, a site of mixed (diurnal and semidiurnal) tides. Diurnal tides are subinertial at this latitude, and once per day a trapped tide leads to large flows through the channel giving rise to tidal excursion lengths comparable to the width of the ridge crest. During these times, energetic turbulence is observed in the channel, with overturns spanning almost half of the full water depth. A high-resolution, nonhydrostatic, 2.5-dimensional simulation is used to interpret the observations in terms of the advection of a breaking tidal lee wave that extends from the ridge crest to the surface and the subsequent development of a hydraulic jump on the flanks of the ridge. Modeled dissipation rates show that turbulence is strongest on the flanks of the ridge and that local dissipation accounts for $28 \%$ of the energy converted from the barotropic tide into baroclinic motion.
\end{abstract}

\section{Introduction}

The direct generation of turbulence by the interaction of the barotropic tide with topography provides an energy pathway linking the ocean's largest scales to its smallest. This "near-field" turbulence drives mixing and water mass modification close to topography in the deep ocean and has far-reaching influence over regional- and basin-scale circulations (Hasumi and Suginohara 1999; Simmons et al. 2004; Osafune and Yasuda 2013; Melet et al. 2013). Understanding the magnitude and distribution of this mixing is challenging because of the wide range of oceanic conditions under which it occurs and the different turbulence generating phenomena that may be present.

\footnotetext{
* Supplemental information related to this paper is available at the Journals Online website: http://dx.doi.org/10.1175/JPO-D-150021.s1.

${ }^{+}$Current affiliation: Massachusetts Institute of Technology, Cambridge, Massachusetts.
}

Corresponding author address: R. C. Musgrave, Massachusetts Institute of Technology, 77 Massachusetts Avenue, Cambridge, MA 02139

E-mail: rmusg@mit.edu
In this paper we examine the specific processes that link the barotropic tide to near-field turbulence in a channel transecting the crest of the Mendocino Ridge in the eastern Pacific. We use both in situ observations and a numerical model to build a detailed view of the phenomenology present at this site. Intense turbulence has been observed close to topography via the generation of tidal lee waves and hydraulic jumps at deep-ocean sites such as Hawaii (Klymak et al. 2008) and Luzon Strait (Alford et al. 2011), as well as shallower locations such as the Kuril Straits (Nakamura et al. 2010). At the Mendocino Ridge we observe these phenomena and are able to clearly identify turbulence associated with radiating internal waves in our observations.

An important parameter describing both the nature of the response and the extent to which it is nonlinear is the nondimensional tidal excursion length

$$
l_{\mathrm{exc}}=\frac{U_{c}}{\omega L},
$$

where $U_{c}$ is the peak tidal speed, $\omega$ is the tidal frequency, and $L$ is a characteristic topographic width (defined in section 2a). We follow Klymak et al. (2010a), defining $U_{c}$ at the crest of the ridge, since for tall topography this is the speed that has most relevance to near-crest 
dynamics. Where excursion lengths are much greater than 1, tidal lee waves are often approximated as quasi steady (Farmer and Smith 1980). However, at the Mendocino Ridge, $l_{\mathrm{exc}} \approx 1$, and we use the framework outlined by Bell (1975) for oscillatory stratified flow over small topography that extends from infinitesimal excursion length $l_{\text {exc }} \rightarrow 0$ (the acoustic limit) to arbitrarily long excursion length $l_{\text {exc }} \rightarrow \infty$ (the lee-wave limit). In the acoustic limit, an internal tide is generated at the fundamental frequency, while in the lee-wave limit, Bell's solution reverts to that of a classic steady lee wave (Gill 1982). For intermediate, finite excursion length flows, these limits are explicitly connected by the generation of an internal wave response at both the forced and harmonic frequencies. It is the time-dependent superposition of this multifrequency response that generates transient (tidal) lee waves close to the ridge. As for classic steady lee waves, Bell's solution is only strictly valid for small topography with shallow slopes. Nevertheless, we find the conceptual framework useful at the Mendocino Ridge where the topography is tall, and, using the numerical model to aid our interpretation, we observe tidal lee waves near the ridge arising from the time-dependent constructive interference of both fundamental and higher harmonic wave patterns. Tidal lee waves have steep characteristic slopes because of the influence of high-frequency harmonics.

We distinguish between turbulence arising from the nonlinear steepening and breaking of radiating tidal lee waves described above and turbulence associated with flow separation, which we attribute to transient hydraulic jumps. These form on the lee side of the topography downstream of a fast, cross-ridge jet that is hydraulically controlled at the ridge crest. The layer Froude number of the jet is the ratio of the mean speed in the jet $\bar{U}$ to the speed of interfacial waves along the jet:

$$
\operatorname{Fr}_{l}=\frac{\bar{U}}{N l}
$$

where $N$ is the Brunt-Väisälä frequency, and $l$ is the layer thickness (Winters and Armi 2013). Though lee waves and hydraulic jumps are often discussed together, we find it useful to distinguish them as the bottom accelerated jet that forms over tall, steep topography that generates turbulence even when the radiating wave component of the response is very small, for example, when the tide is subinertial.

A distinct parameter from the layer Froude number, is the topographic Froude number

$$
\mathrm{Fr}=\frac{U_{c}}{N h},
$$

which determines the ratio of the vertical displacement of a fluid parcel $\delta=U_{c} / N$ to the height of the bathymetry $h$. Fluid parcels deeper than $\delta$ below the ridge crest are blocked on one side of the topography when $\mathrm{Fr}<1$ (Farmer and Smith 1980). For steady flows, Baines and Hoinka (1985) showed that for large values of $\mathrm{Fr}$, overturning and rotors occur downstream of the obstacle, phenomena that also occur in oscillatory flows (Legg and Huijts 2006).

Starting with Farmer and Smith (1980), much of the phenomenology of tidal lee waves has been described in terms of trapped modes, with large-amplitude tidal currents trapping increasingly faster (lower mode) waves. This quasi-steady approach is particularly useful for understanding the vertical structure of the flow at the crest (Klymak et al. 2010b) but provides little guidance on the time dependence of the flow, in particular how internal tide generation is linked to the generation of transient lee waves at large excursion lengths. Our discussion of these processes in terms of Bell's theory complements this modal description in a framework that enables a more general understanding of the timedependent wave dynamics of the response. This is particularly useful when the forcing tide contains more than one frequency, as the linear response can be considered simply as a superposition of the frequency responses to each of the forcing constituents.

At the Mendocino Ridge the predominant tidal constituents are diurnal $\left(\mathrm{K}_{1}\right)$ and semidiurnal $\left(\mathrm{M}_{2}\right)$. The diurnal constituent is subinertial at this latitude and does not generate a radiating internal tide at this frequency. However, its baroclinic response dominates the formation of tidal lee waves at the ridge. The nature of the generated trapped tide and its influence on regional energetics is mainly dealt with in a second paper (R. C. Musgrave et al. 2016, unpublished manuscript, hereinafter M16b), where we run a 3D numerical model that can reproduce the spatial scales of the wave. The main finding of that paper is that the trapped wave determines the time dependence of the tidally driven turbulence at the ridge crest and increases the fraction of tidal energy dissipated in the near-field compared to that expected from a semidiurnal forcing alone. In this paper, we examine the spatial structure of turbulence close to the ridge crest and the flux of radiating (superinertial) waves in our 2D numerical model. We find that the generation of harmonics at the topography is significant, leading to the formation of tidal lee waves and energy fluxes at harmonic frequencies that account for at least $30 \%$ of the total radiating energy northward of our site. Using our numerical model we estimate that the fraction of energy extracted from the barotropic tide and dissipated near the ridge is $28 \%$, in contrast to measurements by 


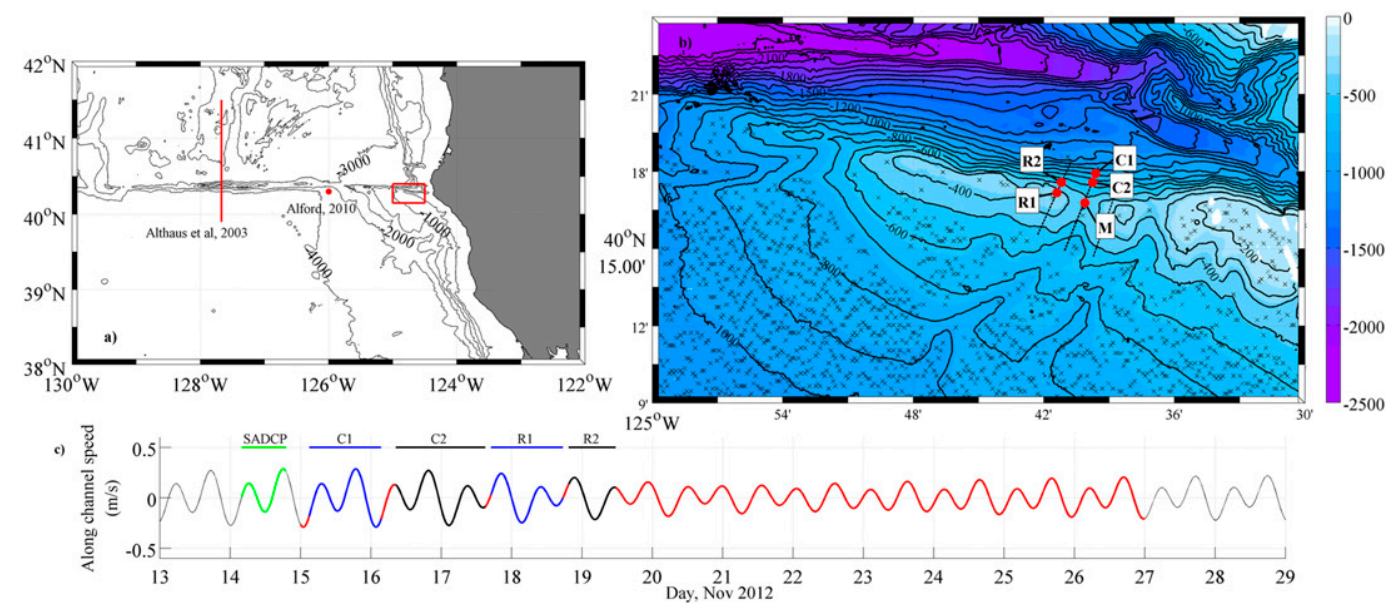

FIG. 1. (a) Regional map showing the Mendocino Ridge and continental shelf of the West Coast United States, and locations of previous studies in the area. (b) Stations C1, C2, R1, and R2 were LADCP/CTD stations in the channel (C) and ridge (R). A subsurface mooring was in place at M. SADCP transects are black dashed lines. Crosses represent regions of $\mathrm{M}_{2}$ near-critical slope. (c) Time series of TPXO-predicted along-channel component of the barotropic flow during observations. Red line is the period mooring was in place, green line indicates time of SADCP transects, and alternating blue and black lines are times of station time series $\mathrm{C} 1, \mathrm{C} 2$, $\mathrm{R} 1$, and R2.

Althaus et al. (2003, hereinafter AL03) at a location farther west along the ridge (in the deep ocean), where they infer that only $1 \%$ of the energy extracted from the barotropic tide is dissipated near the ridge.

Analytical and numerical work to date has focused on near-field turbulence over two-dimensional bathymetry (Legg and Klymak 2008; Klymak et al. 2010a; Rapaka et al. 2013), and the influence of small-scale threedimensionality remains relatively unexplored. An outstanding question is to what extent parameterizations such as that proposed by Klymak et al. (2010a) are generalizable beyond the two-dimensional, singlefrequency constituent that the parameterization was designed for. Though we do not address this question fully in this study, we are able to use a 12-day moored time series from the center of the channel to estimate a power-law relation between tidal velocity and dissipation rate at this location.

The paper has six sections. In section 2, we detail the site location, observations, analysis methods, and numerical model setup. In section 3, we present results from the observations and model and assess how well the model reproduces the data. We interpret the observations in the channel with the aid of the model in section 4 and clearly distinguish between the two different turbulence-generating phenomena in the channel: tidal lee waves and hydraulic jumps. In section 5, we relate tidally averaged dissipation rates to tidal velocity from a 12-day moored time series at the center of the channel. Finally, in section 6 we summarize our results.

\section{Experimental details}

\section{a. Site location}

The study area is situated around $30 \mathrm{~km}$ from the North American coast in the eastern Pacific, at a latitude of $40^{\circ} \mathrm{N}$. Ship-based observations were obtained in and around a small channel transecting the crest of the Gorda Escarpment, where the Mendocino Ridge joins the continental shelf (Fig. 1a). The Mendocino Ridge is a large-scale bathymetric feature, rising 1000 and $2000 \mathrm{~m}$ from the abyssal plains to the north and south, respectively, and extending over $2000 \mathrm{~km}$ westward into the Pacific at a depth greater than $1000 \mathrm{~m}$ for most of its length. AL03 analyze a series of measurements in a longitudinal line over the ridge in the open ocean to the west of our site. They identify the ridge as a significant internal tide source in the northeast Pacific, generating a total semidiurnal tidal flux (north and south) of up to $7 \mathrm{~kW} \mathrm{~m}^{-1}$. The importance of this site for the generation of internal tides is supported by the moored time series of Alford (2010) located to the south of the ridge. Heightened dissipation in a layer up to $500 \mathrm{~m}$ thick close to the crest of the ridge was observed by AL03, suggesting the presence of turbulent near-ridge phenomena.

On large scales, the ridge may reasonably be considered to be two-dimensional. However, the phenomena giving rise to near-field turbulence occur on scales of order of a few kilometers and consequently are influenced by "small-scale" bathymetric features such as the channels, canyons, and hills present along the crest and flanks of the ridge. Our study site focuses on a channel 
with a width of around $4 \mathrm{~km}$ and a crest depth of approximately $500 \mathrm{~m}$. It represents a localized drop in the height of the ridge crest of about $200 \mathrm{~m}$ (Fig. 1b). Crosses represent regions of slope that are near-critical, with slopes within \pm 0.01 of the semidiurnal $\left(\mathrm{M}_{2}\right)$ characteristic at a constant stratification of $3 \mathrm{cph}$, appropriate for these depths. In the immediate vicinity of the crest, the slopes to the north and south are steep and supercritical to $\mathrm{M}_{2}$ internal tides. However, the southern slope shallows to a near-critical slope around $5 \mathrm{~km}$ away from the crest.

Barotropic flows at the location of the mooring were estimated using the TOPEX/Poseidon Global Inverse Solution 7.2 (TPXO7.2) West Coast United States tidal model (Egbert and Erofeeva 2002), hereinafter referred to as TPXO, which uses satellite altimetric data to constrain solutions to the Laplace tidal equations on a $1 / 30^{\circ}$ bathymetric grid (about $3 \mathrm{~km}$ at this latitude). A time series for predicted across-ridge flows at the mooring during the period of observations (Fig. 1c) shows that, like much of the eastern Pacific, this site is subject to a mixed tide, with diurnal $\left(\mathrm{K}_{1}\right)$ and semidiurnal $\left(\mathrm{M}_{2}\right)$ constituents dominating and having amplitudes of 0.38 and $0.62 \mathrm{~m}$, respectively. We use the peak cross-ridge velocity predicted by TPXO at the mooring site during the observation period of $U_{c}=0.4 \mathrm{~m} \mathrm{~s}^{-1}$ to estimate the tidal excursion length at the crest as $U_{c} / \omega_{\mathrm{M}_{2}} \approx 3 \mathrm{~km}$. The relevant topographic length scale is determined by the ridge width at a depth $\delta=U_{c} / N$ below the crest-below this depth fluid is blocked and does not pass over the ridge. In this case, we estimate the topographic length scale to be around $4 \mathrm{~km}$, giving a predicted nondimensional excursion length for this channel of $l_{\mathrm{exc}} \approx 1$, indicative of the importance of nonlinearity at this location. As the observed flow speeds were more than double the TPXO predictions, this excursion distance is a lower bound on the observations discussed here.

For this ridge, we estimate $\mathrm{Fr} \approx 0.1$, meaning that the bulk of the upstream water at a given phase of the tide is blocked and does not surmount the crest.

\section{b. Observations}

Measurements were obtained in November 2012 using a combination of ship-based and moored instruments. A subsurface mooring was placed close to the center of the channel (marked M in Fig. 1b) from 15 to 27 November 2012. The mooring composed a $75-\mathrm{kHz}$, down-looking, long-range acoustic Doppler current profiler (ADCP) installed in the upper float, 16 temperature loggers (SBE56) and two pressure-temperature-conductivity loggers (SBE37) sampling at 1 and $0.01 \mathrm{~Hz}$, respectively. Most temperature loggers were spaced approximately $20 \mathrm{~m}$ apart and spanned the central region of the mooring; however, two additional temperature loggers were placed just above the anchor and just below the subsurface float and were separated from the rest of the vertical array by 40 and $30 \mathrm{~m}$, respectively. The SBE37s were located at the subsurface float (at a nominal depth of $100 \mathrm{~m}$ ) and just above the anchor (at a depth of $460 \mathrm{~m}$ ) and provided an indication of how far the mooring was knocked down by the strong currents as well as the salinity-temperature properties of the water masses present. Based on pressure records just below the upper float (nominally $440 \mathrm{~m}$ above the bottom), the mooring knockdown was up to $170 \mathrm{~m}$ during periods of strong flow. To determine the depths of temperature loggers, we compute the static solution to the mooring shape (curvature) by balancing the drag and buoyancy on each element of the mooring for observed flow speeds and knockdowns (Dewey 1999). The solutions were found to be consistent with the observed pressure records, and we estimate maximum errors in the vertical coordinate to be a maximum of $10 \mathrm{~m}$ (and much less during periods of weak flow).

Dissipation rates at the mooring are inferred from the 1-Hz temperature loggers using the method described in Zhang and Moum (2010). Spectra of temperature gradients computed from 120-s segments are fitted to Bachelor spectra in the inertial-convective subrange to establish the dissipation rate of thermal variance $\chi$, which is related to the turbulent diffusivity of heat $K_{T}$ by the Osborne-Cox relation (Osborn and Cox 1972). Under the assumptions that turbulent diffusivities of heat and momentum are equal $\left(K_{T}=K_{\nu}\right)$, and that there is a local balance between turbulent kinetic energy, shear production, and buoyancy, the turbulent dissipation rate may be solved for.

Densities at each of the temperature loggers were inferred from a lookup table of salinities and temperatures generated from combined conductivity-temperaturedepth (CTD) station data and SBE37 mooring data. Temperature-salinity $(T-S)$ relations indicate that the water mass properties around the mooring were fairly homogeneous over the duration of the measurements, and the $T-S$ relation was monotonic. The largest variance in salinities for a given temperature class were associated with warmer surface waters, and we estimate a maximum error in our inferred densities close to the surface of $\pm 0.12 \mathrm{~kg} \mathrm{~m}^{-3}$.

With the mooring in place, four CTD-LADCP stations were undertaken, ranging in duration from 20 to $30 \mathrm{~h}$. Two $300-\mathrm{kHz}$ lowered acoustic Doppler profilers (LADCPs) were fixed to the CTD cage, one oriented looking upward, the other oriented looking down, providing 8-m binned velocity data to within a few meters of the bottom. Data were processed using the LDEO_IX 

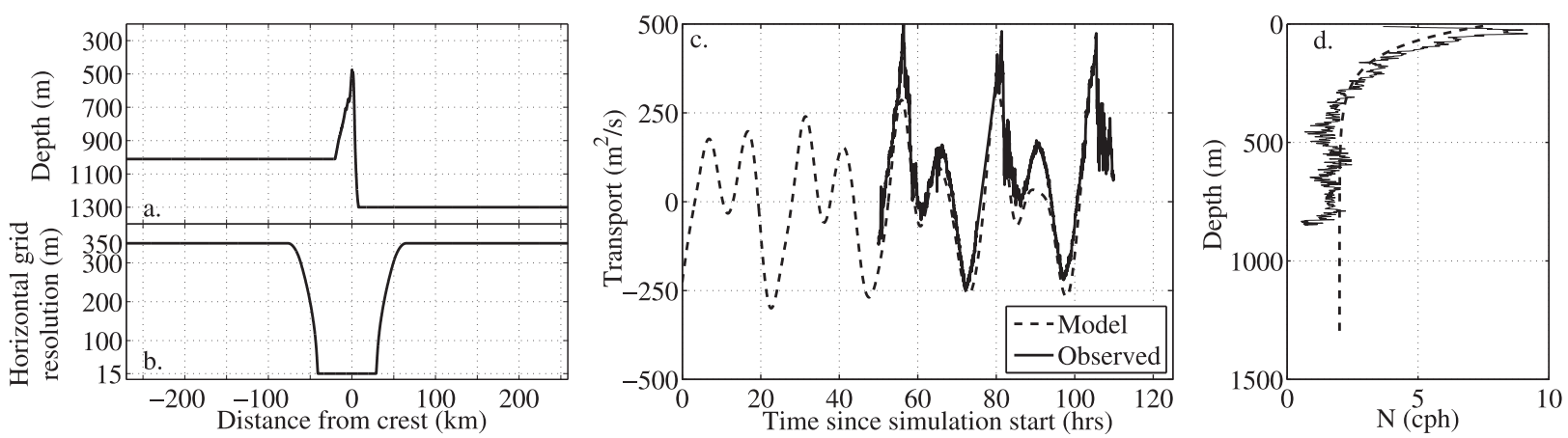

FIG. 2. (a) Model bathymetry. (b) Horizontal grid resolution. (c) Model volume transports (dashed line) compared to observations (solid line) through stations $\mathrm{C} 1$ and $\mathrm{C} 2$. (d) Model stratification (dashed line) compared to mean stratification (solid line) at station C1.

software (Visbeck 2002) and are presented as along- and cross-channel components (a $17^{\circ}$ clockwise rotation of the coordinates). Two channel stations ( $\mathrm{C} 1$ and $\mathrm{C} 2$ ) were 2 and $3 \mathrm{~km}$ to the north of the mooring along the centerline of the channel at the 700- and 800-m isobath, respectively. The two ridge stations ( $\mathrm{R} 1$ and $\mathrm{R} 2$ ) were west of the channel, on the ridge crest (R1 at $350 \mathrm{~m})$, and just north of it (R2 at $450 \mathrm{~m})$. Station locations are marked in Fig. 1b; however, in this paper we only report on measurements at $\mathrm{C} 1, \mathrm{C} 2$, and the mooring. The CTD-LADCP package was nominally lowered to between 5 and $10 \mathrm{~m}$ from the bottom, but currents occasionally in excess of $1.2 \mathrm{~m} \mathrm{~s}^{-1}$ made accurate depth positioning of the CTD-LADCP package difficult, inhibiting our ability to profile close to the bottom during some phases of the tide.

Turbulent dissipation rates on station were calculated from density inversions in CTD profiles by computation of the Thorpe scale of the overturn. The Thorpe scale is then related to the Ozmidov scale to estimate the turbulent dissipation rate (Thorpe 1977; Dillon 1982). Spurious overturns were removed using the tests described in Galbraith and Kelley (1996) and Gargett and Garner (2008).

To help establish the length scales and timing of ridgetop flows before finalizing the station locations, 10 crossridge transects of velocity were obtained over a $13-\mathrm{h}$ period using the $75-\mathrm{kHz}$ shipboard acoustic Doppler current profiler (SADCP). The ship steamed repeatedly along the three black lines marked in Fig. 1 in a butterfly pattern at 7 knots $\left(3.6 \mathrm{~m} \mathrm{~s}^{-1}\right)$, passing down the center of the channel every $1.5 \mathrm{~h}$ and transecting the eastern and western adjacent ridges every $3 \mathrm{~h}$. Each transect took around $0.5 \mathrm{~h}$ to complete, resulting in negligible temporal evolution in each of these snapshots. The bottom depth ranged between 300 and $800 \mathrm{~m}$, and the high density of scatterers in this coastal location meant that the SADCP provided a detailed view of the flow over the ridge as the tide progressed. Data were processed and gridded into 1-min bins using the University of Hawaii Data Acquisition System and, as with the LADCP data, are presented in subsequent sections rotated into along- and cross-channel components. Sidelobe interference typical of acoustic instruments contaminates the lower $\sim 100 \mathrm{~m}$ of SADCP velocity data and is excluded from the analysis.

\section{c. Numerical model}

To help provide context for the observations, we used the Massachusetts Institute of Technology General Circulation Model (MITgcm; Marshall et al. 1997) to run a high-resolution, 2.5-dimensional simulation along the center of the channel. The model is 2.5 -dimensional because of the inclusion of Coriolis terms in the horizontal momentum equations, which enables Coriolis rotation of the flow without allowing any gradients in the along-ridge dimension. The relatively small scale of this simulation makes an $f$-plane approximation appropriate, and we used a value of the Coriolis frequency $f$ corresponding to $40^{\circ} \mathrm{N}$. We ran the model in nonhydrostatic mode, with a central grid resolution of $d x=d z=15 \mathrm{~m}$, telescoping outside the domain of interest to $d x=350 \mathrm{~m}$ close to the lateral boundaries (Fig. 2b). The simulation had a total of $5.3 \times 10^{5}$ grid points and was run for 108 simulation hours. The domain was $1300 \mathrm{~m}$ deep and $530 \mathrm{~km}$ long, large enough that internal waves generated by the topography did not reflect back from the boundaries into the domain of interest during the simulation time. A $70 \mathrm{~m} \times 90 \mathrm{~m}$ gridded multibeam bathymetry extracted from the NOAA database (http://maps.ngdc.noaa.gov/viewers/ bathymetry/) was used to create a bathymetric profile along the center of the channel (Fig. 2a). Comparisons between this bathymetry and ship-based measurements showed good agreement (not shown). The bathymetric profile was padded with flat bathymetry away from the crest and smoothed to aid numerical stability. 
Model forcing was derived by fitting a five frequency $\left(\mathrm{M}_{2}, \mathrm{~K}_{1}\right.$, and harmonics $3 \times \mathrm{K}_{1}, 2 \times \mathrm{M}_{2}$, and $\left.5 \times \mathrm{K}_{1}\right)$ harmonic fit for amplitude and phase to the observed transports from stations $\mathrm{C} 1$ and $\mathrm{C} 2$. The fitted amplitudes were 161 and $147 \mathrm{~m}^{2} \mathrm{~s}^{-1}$ for the $\mathrm{M}_{2}$ and $\mathrm{K}_{1}$ constituents, respectively: a significantly larger relative contribution of the $\mathrm{K}_{1}$ constituent compared to that predicted by TPXO for this location (see section 2a). All other constituents had amplitudes less than $20 \mathrm{~m}^{2} \mathrm{~s}^{-1}$. The reconstructed time series matched the phase of the observed transport well (Fig. 2c) but underpredicted the large peaks in northward flow in the observations by almost $200 \mathrm{~m}^{2} \mathrm{~s}^{-1}$. However, because of the peaked nature of the observed transport, this only resulted in significant errors in forcing for around $3 \mathrm{~h}$ during peak flow in station $\mathrm{C} 1$. Transport errors during station $\mathrm{C} 2$ were significantly less. To allow the model to spin up, the reconstructed forcing time series was shifted by $50 \mathrm{~h}$ so that the time corresponding to the start of station $\mathrm{C} 1$ occurred $50 \mathrm{~h}$ after initialization. Model forcing was imposed by the addition of a body force to each of the horizontal momentum equations such that the flow in the deeper region to the north of the channel was rectilinear with the desired transports and frequencies ( $\mathrm{Di}$ Lorenzo et al. 2006). Coriolis effects generated a barotropic rotation in the shallow region to the south. Inflowoutflow boundary conditions at the lateral boundaries were set to be consistent with barotropic flow induced by the body force in the absence of the ridge.

The model's initial stratification was set to an exponential profile fitted to the $\mathrm{C} 1$ station mean stratification and extrapolated to the depth of the simulated domain (Fig. 2d). The absence of a restratifying process in the model meant that the density profile gradually diffused over the course of the simulation, and the explicit vertical diffusivity was made small to minimize this effect.

We experimented with two turbulence closure schemes: constant background viscosities and horizontal-vertical diffusivities (viscosity: $\nu=1 \times 10^{-2} \mathrm{~m}^{2} \mathrm{~s}^{-1}$; horizontal diffusivity: $\kappa_{H}=2 \times 10^{-2} \mathrm{~m}^{2} \mathrm{~s}^{-1}$; and vertical diffusivity: $\kappa_{z}=6 \times 10^{-4} \mathrm{~m}^{2} \mathrm{~s}^{-1}$ ) and reduced background viscosities and diffusivities combined with an implementation of the Smagorinsky turbulence closure scheme, which dynamically increases viscosity where strain rates are high $(\nu=$ $2 \times 10^{-3} \mathrm{~m}^{2} \mathrm{~s}^{-1}, \kappa_{H}=2 \times 10^{-3} \mathrm{~m}^{2} \mathrm{~s}^{-1}$, and $\kappa_{z}=6 \times$ $10^{-4} \mathrm{~m}^{2} \mathrm{~s}^{-1}$ ). Smagorinsky coefficients of $C_{s}^{2}=0.02,0.03$, and 0.04 were tested. The goal of these simulations was to ensure that the grid-scale Reynolds and Peclet numbers remain less than one, such that viscosity and diffusivities are explicitly accounted for by the model. For all simulations, numerical accuracy was evaluated both by the appearance of grid-scale noise and the residual closure of a postsimulation computed kinetic energy budget. All simulations reproduced the gross features of the flow, but the simulation with $C_{s}^{2}=0.03$ and relatively smaller background viscosity and lateral diffusivity is presented here because it is both numerically smooth and captures the steepness of isopycnals before the onset of breaking. Time stepping was performed using a quasi-second-order Adams-Bashforth method. The MITgcm employs a second-order centered advection scheme for momentum, and we used a one-step, seventh-order, monotonicitypreserving advection scheme for temperature (Daru and Tenaud 2004).

\section{Results}

\section{a. The spatial evolution of flow through the channel: Flow snapshots}

Figure 3 shows a series of along- and cross-channel velocity snapshots acquired using the SADCP as the ship transected the center of the channel 10 times over a period of roughly $13 \mathrm{~h}$ on 14 November 2012. The transects show the development of two northward tides in the along- and cross-channel flows (where the coordinates are rotated clockwise $17^{\circ}$ from geographic). The first northward tide initiates in Fig. 3a, with a beamlike feature extending from the southern flank of the ridge, generating northward currents at depths shallower than $400 \mathrm{~m}$ on the northern flank. As the tide progresses (Figs. 3a-c), the along-channel flow becomes increasingly bottom intensified, with flows in excess of $1.2 \mathrm{~m} \mathrm{~s}^{-1}$ forming a jet whose separation point on the lee side of the slope continues to deepen until slack tide (Fig. 3c), attaining a maximum depth of $700 \mathrm{~m}$ at kilometer 5, where it jumps up to $400 \mathrm{~m}$. This bottomintensified jet and downstream separation are consistent with other observations and numerical studies of these phenomena (Klymak et al. 2010b; Abe and Nakamura 2013). In Figs. 3b and 3c, weaker northward flow is also present close to the surface in a structure that exhibits oscillations on scales of order $1 \mathrm{~km}$ (Fig. 3c, shallower than $200 \mathrm{~m}$ and between 3 and $5 \mathrm{~km})$. Once the tide reverses, the jet breaks up and weak southward flow is established.

The second northward tide (Figs. $3 \mathrm{~h}-\mathrm{j}$ ) is markedly different from the first, with all of the along-channel transport accommodated in the upper layer and persistent weak southward flows at depth. The lack of interaction of the along-channel transport with channel crest means that no bottom-intensified jet is generated and anticipates our finding of negligible turbulent dissipation during this phase of the tide. The total alongchannel transport in this second northward tide is around $30 \%$ of the transport observed in the first and 


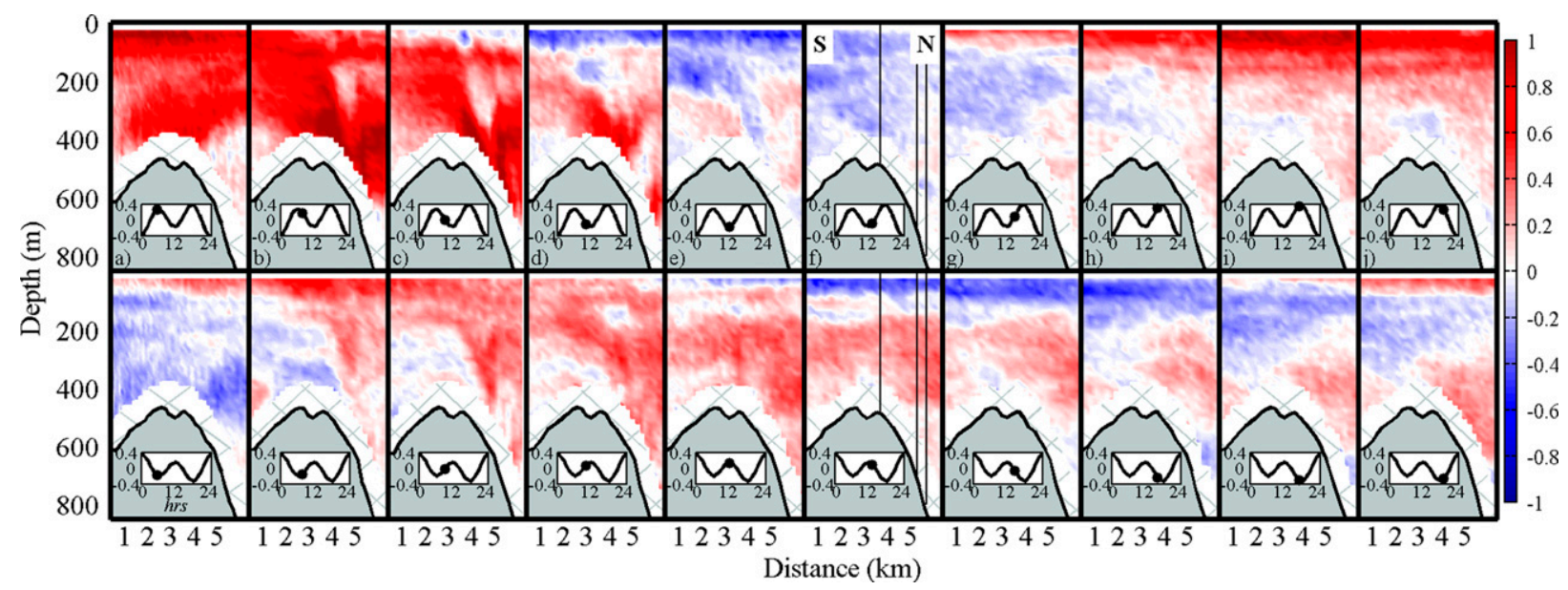

FIG. 3. SADCP snapshots of velocity rotated into (top) along- and (bottom) cross-channel components through the center of the channel as the tide progresses over around $13 \mathrm{~h}$. Insets show TPXO-predicted barotropic speeds $\left(\mathrm{m} \mathrm{s}^{-1}\right)$, with dots indicating the time of the snapshot. Vertical lines in (f) show locations of mooring (M) and CTD-LADCP stations C1 and C2. Note the different nature of adjacent northward tides in panels (b) and (i).

represents the strong diurnal inequality that characterized observations during this field experiment. Insets in Fig. 3 show the TPXO-predicted barotropic transport for this location, which, while matching the phase of observed transports reasonably well, do not show a significant peak-to-peak change in the amplitudes of the northward tides. M16b show that diurnal-trapped internal tides are responsible for both the large, observed, daily inequality and the surface-confined nature of the weak, northward tide.

Cross-channel flows (lower panels, Fig. 3) have magnitudes of around $50 \%$ of the along-channel flows and are predominantly eastward in the region of strong shear on the forward face of the lee wave. Sections across the adjacent ridge crest (not shown) exhibit smaller transports but qualitatively similar features, including the formation of tidal lee waves during alternate (strong) northward tides.

\section{b. 12-day tidal evolution at the center of the channel}

Figure 4 shows the 12-day time series of (Fig. 4a) along- and (Fig. 4b) cross-channel velocities at the mooring in the center of the channel, with isopycnals overlaid. A strong diurnal inequality distinguishes the first part of the time series where very large northward and southward tides $\left(>1 \mathrm{~m} \mathrm{~s}^{-1}\right)$ alternate once per day with much weaker tides $\left(<0.3 \mathrm{~m} \mathrm{~s}^{-1}\right)$. The inequality persists for much of the first part of the record before gradually becoming weaker as the timings of peak flows associated with the dominant $\mathrm{K}_{1}$ and $\mathrm{M}_{2}$ components shift in relation to one another. Intermittent regions of missing data at shallow depths indicate times when the upper float of the mooring was knocked down by strong currents. Periods of overlap between the mooring and station time series are indicated above (Fig. 4a) and are discussed in section 3c. Depth-averaged velocities at the mooring (not shown) indicate that currents are approximately rectilinear and oriented at an angle of about $-20^{\circ}$ with respect to the channel axis, with along- and cross-channel flows approximately in phase but cross-channel flows having a magnitude of around half that of alongchannel flows.

The depth-time evolution of turbulent dissipation rates inferred from the $1-\mathrm{Hz}$ temperature loggers show sloping patterns associated with tide reversals (Fig. 4c). During the first part of the record where the diurnal inequality is large, both tide reversals during the stronger daily tides progress downward from the surface with time and are associated with high isopycnal strain and inferred dissipation rates (e.g., from 15 to 20 November). Here, we loosely define regions of high strain as where isopycnal separations are larger than in an average profile. In addition to the turbulence in the sloping features, enhanced dissipation is present near the bottom in a $\sim 150$-m-thick turbulent layer of dense water that reaches the mooring during peak tidal flows. During neap tide (22-23 November 2012), flow speeds are smaller and turbulence is generally reduced. The time evolution of depth-integrated dissipation rate (black) and mean along-channel velocity (blue) is shown in Fig. 4d. Depth-integrated dissipation rates have peaks associated with the slanted high dissipation rate structures that occur twice per day with values of around $10 \mathrm{~W} \mathrm{~m}^{-2}$. Peak dissipation rates lag peak tidal flows by around $3 \mathrm{~h}$. 


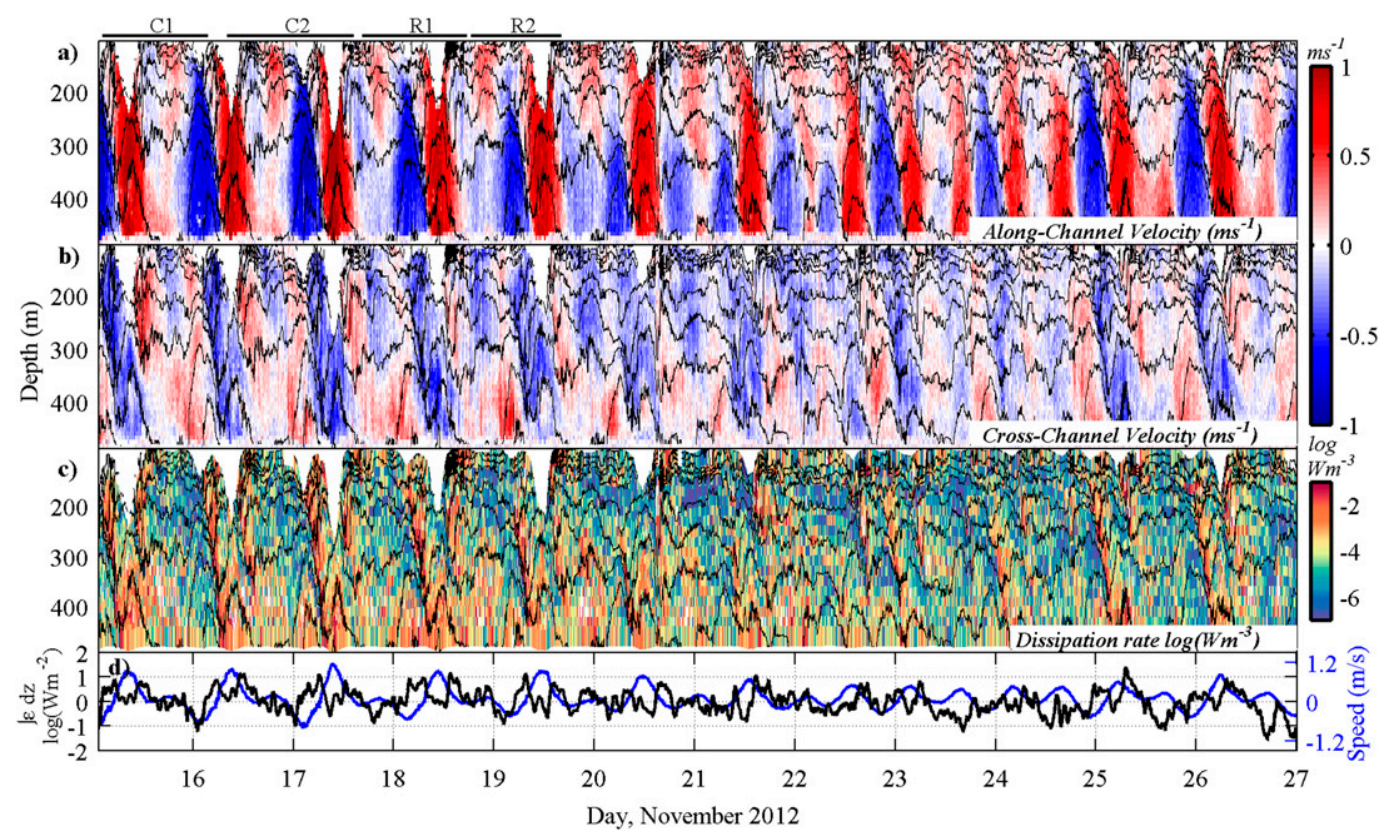

FIG. 4. Mooring time series: Upper three panels are (a) along-channel velocity, (b) cross-channel velocity, (c) turbulent kinetic energy dissipation rate $\left(\varepsilon\right.$; color). In (a)-(c) isopycnals are contoured (intervals $0.2 \mathrm{~kg} \mathrm{~m}^{-3}$, range 1025.4-1027.1 $\mathrm{kg} \mathrm{m}^{-3}$ ). (d) Depth-integrated dissipation rate (black) and depth-mean along-channel speed (blue).

\section{c. Velocity, density, and turbulent dissipation rates in the channel}

SADCP transects showed jet separation on the northfacing flank at around 700-m depth (Fig. 3c); therefore, channel stations were positioned just downstream of separation (C1: 800-m isobath) and at separation (C2: 700-m isobath). Time series of along- and cross-channel flow and turbulent dissipation rate from overturns show similar features (Figs. 5b,c,d): flows are asymmetric in time with distinguishable patterns of enhanced turbulence associated with tide reversals. Consistent with simultaneous moored measurements (Figs. 5g,h,i), a strong diurnal inequality causes alternate tides to be much weaker, with the weak tides (e.g., 14002200 UTC 16 November) being relatively nonturbulent. Strong northward tides are bottom intensified, with peak flow speeds reaching up to $1.2 \mathrm{~m} \mathrm{~s}^{-1}$ at depth and weaker surface flows above $200 \mathrm{~m}$, features that can also be seen in the SADCP snapshots of the flow (e.g., Fig. 3c). The different character of the weak compared to the strong northward tides is also apparent in these station time series, with the weak northward flows surface confined and having very small velocities below $350 \mathrm{~m}$. Transports at each station peak at around $500 \mathrm{~m}^{2} \mathrm{~s}^{-1}$ and are approximately equal at both $\mathrm{C} 1$ and $\mathrm{C} 2$, indicating little lateral flow convergence between the stations.

At both stations, strong southward (on ridge) flow is associated with raised isopycnals and few overturns, and strong northward (off ridge) flows are highly turbulent. The transition between strong southward and northward tides progresses from the surface to depth over the course of around $7 \mathrm{~h}$ and, as in the mooring time series, is associated with significant isopycnal strain and turbulence. Each strong northward tide has two distinguishable patterns of turbulence associated with it; the first follows the sharp transition from southward to northward flow, progressing downward in time (e.g., 0200-0800 UTC, 15 and 17 November 2012); the second occurs later in the cycle as the strong northward tide relaxes (0800-1200 UTC, 15, 16, and 17 November 2012). The largest overturns were measured during this relaxation period at station $\mathrm{C} 2$, with heights up to $380 \mathrm{~m}$ just after peak flow with middepths around 350-m depth (Fig. 5d). Depth-integrated dissipation rates are shown in Fig. 5e and show maximum values of up to $10 \mathrm{~W} \mathrm{~m}^{-2}$ at $\mathrm{C} 1$ and $100 \mathrm{Wm}^{-2}$ at $\mathrm{C} 2$ occurring around $3 \mathrm{~h}$ after each northward peak flow. The larger values at station $\mathrm{C} 2$ reflect a change in our location with respect to the region of largest breaking. Dissipation rates vary over each tidal period by two orders of magnitude, with high dissipation rates present throughout the strong northward tide.

Concurrent time series of velocity, inferred density, and dissipation rate at the mooring show that tide reversals initiate at approximately the same time as at the CTD stations but progress downward over the entire water column over a shorter period of time (Figs. $5 \mathrm{~g}, \mathrm{~h}, \mathrm{i}$ ). In contrast with the station time series, depth-integrated 

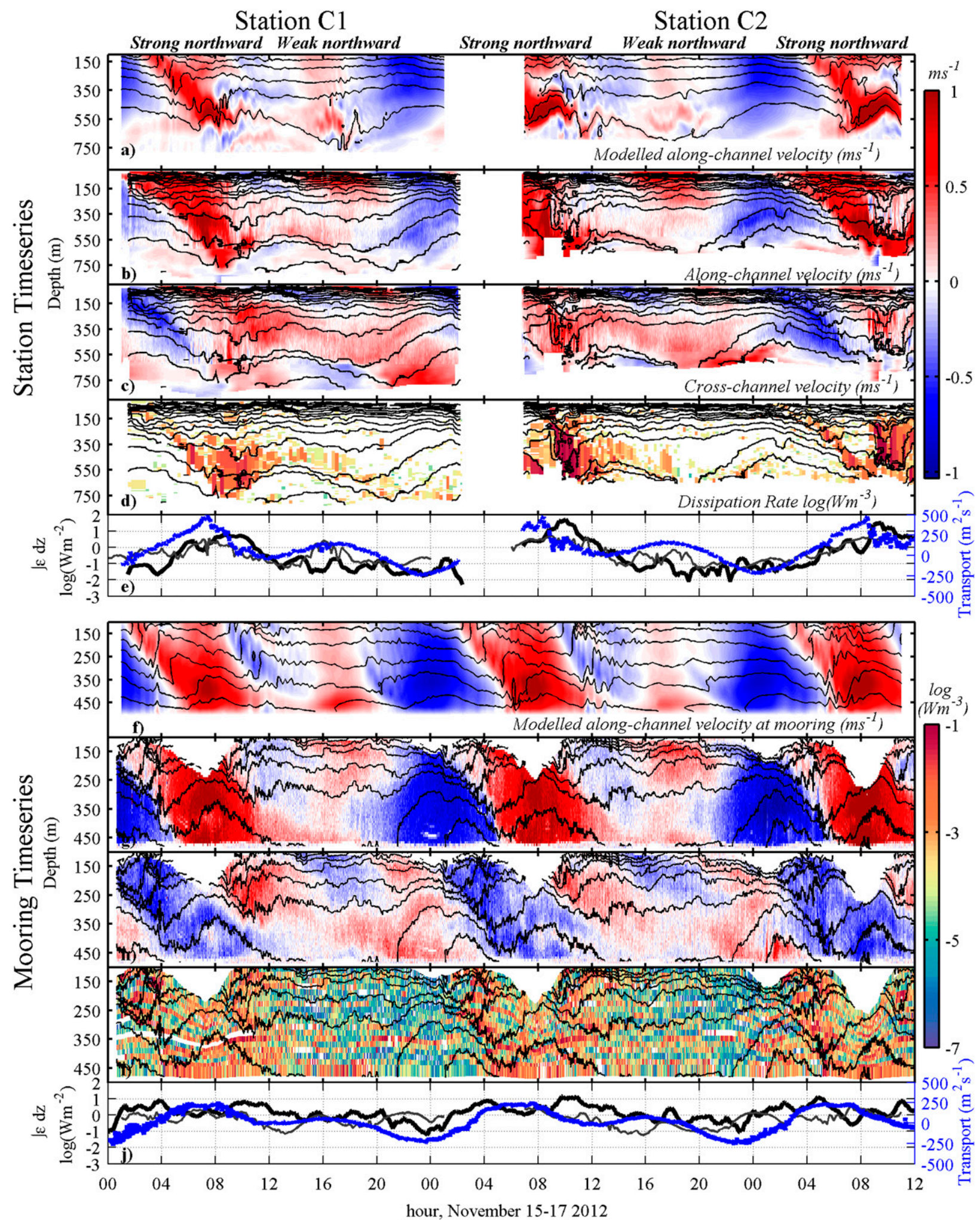

FIG. 5. CTD station time series: (a) Modeled along-channel velocity (color) and isopycnals (contoured, intervals $0.15 \mathrm{~kg} \mathrm{~m}^{-3}, \mathrm{range}$ $1024-1027 \mathrm{~kg} \mathrm{~m}^{-3}$ ); (b),(c) observed along- and cross-channel velocity (color) and isopycnals (contoured, intervals $0.15 \mathrm{~kg} \mathrm{~m}^{-3}$, range $\left.1024.2-1027.2 \mathrm{~kg} \mathrm{~m}^{-3}\right)$; (d) turbulent dissipation rates ( $\varepsilon$; colored) and isopycnals (contoured); and (e) depth-integrated turbulent dissipation rates (black) and velocities (blue). Modeled depth-integrated dissipation rates are thin dark gray lines. (f)-(j) As in (a)-(e), but at mooring. 
dissipation rates at the mooring have two peaks, each of which is associated with a tide reversal (Fig. 5j, black line). The first peak lags strong southward flow and is associated with turbulence formed on the southern flank of the ridge, while the second peak lags strong northward flow and is associated with turbulence observed on the northern flank at the CTD stations $\mathrm{C} 1$ and $\mathrm{C} 2$. Turbulent dissipation rates are also elevated in the dense water that is advected onto the ridge crest during peak northward flows (Fig. 5, 0500-1200 UTC 15, 16, and 17 November 2012). Southward flows tend to be less turbulent, as the weaker tide that precedes the strong southward flow does not generate turbulence on the northern flank.

\section{d. Model assessment}

Station time series extracted from the model at stations $\mathrm{C} 1$ and $\mathrm{C} 2$ and the mooring location after $50 \mathrm{~h}$ of simulation time (Figs. 5a,f) demonstrate good quantitative agreement with observations, particularly during phases of the tide with large transports. Key features are reproduced such as the tide reversal beginning at the surface and extending downward in time before splitting into a bottom-intensified and surface jet with vigorous turbulence between. However, during the weak phase of the tide, differences between the modeled and observed flows arise. In M16b, we find that subinertial trapped waves are important to the tidal flows in the channel: these waves are bottom trapped, with length scales in the along-ridge direction of around $30 \mathrm{~km}$ at $500-\mathrm{m}$ depth. They are associated with significant cross-channel isopycnal slopes and require a fully $3 \mathrm{D}$ model to accurately reproduce their features and match the observations during the weak beat of the tide. Differences between the observations and model also arise in the duration of flow reversals: simulated flow reversals tend to be too short $(5 \mathrm{~h})$, compared to the observed reversals $(7 \mathrm{~h})$. It is possible that these discrepancies arise from the narrowband forcing in the model compared to the much more broadband tidal forcing in the real ocean. In general, simulated and observed flows are in closer agreement at station $\mathrm{C} 2$ than $\mathrm{C} 1$ because of a slightly shallower flow separation in the model than the observations. The discrepancy in flow separation perhaps arises from the relatively smaller transports in the model compared to observations. Despite these differences, overall agreement is sufficiently good that the simulation may be used to interpret features in the time series with confidence.

A postsimulation evaluation of the kinetic energy budget of the model was made for the analysis period. The model exhibits good closure of the budget, with the time-mean residual error more than 5 times smaller than the smallest term in the budget (the kinetic energy dissipation rate). The residual error arises from three sources: discretization errors in the postsimulation calculation of the terms of the budget; errors arising from the time derivative of the kinetic energy that is computed over 10-min output time steps, rather than the 1-s model time step; and errors associated with the numerics, primarily the second-order accurate momentum advection scheme and seventh-order accurate tracer scheme used by the model, which manifest as numerical diffusion. Though the model is 2.5 -dimensional and relies upon a somewhat ad hoc choice of turbulence parameters, the diagnosed turbulent dissipation rates are the same order of magnitude as the observations over most of the analyzed period (Figs. 5e,j; section 4b). Differences arise during peak flow, when the model forcing does not match the transport to observations, and also during the weak tide, when the model generates a small turbulent tidal lee wave that we do not see in the observations because of the presence of trapped topographic waves.

\section{Tidal lee waves and hydraulic jumps}

\section{a. The structure of turbulence and flow in the near field}

In the subsequent discussion we refer to frequencies D1, D2, D3, and D4 as having roughly 1, 2, 3, and 4 cpd, respectively, where D2 includes both the $\mathrm{M}_{2}$ tidal constituent and the second harmonic of $\mathrm{K}_{1}$, D3 is the third harmonic of $\mathrm{K}_{1}$, and $\mathrm{D} 4$ includes the second harmonic of $\mathrm{M}_{2}$ and the fourth harmonic of $\mathrm{K}_{1}$.

Eight snapshots of the modeled flow as it develops over $24 \mathrm{~h}$ are shown in Fig. 6. Time is referenced to model time at $74 \mathrm{~h}$, and the period under discussion corresponds to the time station $\mathrm{C} 2$ was occupied. An animation of this period is included in the supplementary material. The upper panel shows velocity (colored) and density (contoured), and the lower panel shows the evolving model time series at station C2 (Fig. 5a). The analysis period starts with a southward tide at $0 \mathrm{~h}$, which forms a strongly bottom-intensified jet of anomalously dense water over the southern flank of the ridge crest (Fig. 6a, also mooring time series in Fig. 5 at 0000 UTC 15 November). The baroclinic structure of the flow during this phase of the tide is consistent with that of a tidal lee wave, a sloping feature having an alternating southward-northward baroclinic structure (i.e., with the depth mean removed). However, the steep isopycnals and strongly accelerated near-crest flow indicate that nonlinearity is an important part of the dynamics.

The characteristic curves for wave frequencies at D2, D3, D4, and the steady lee wave are shown in Figs. 6a 


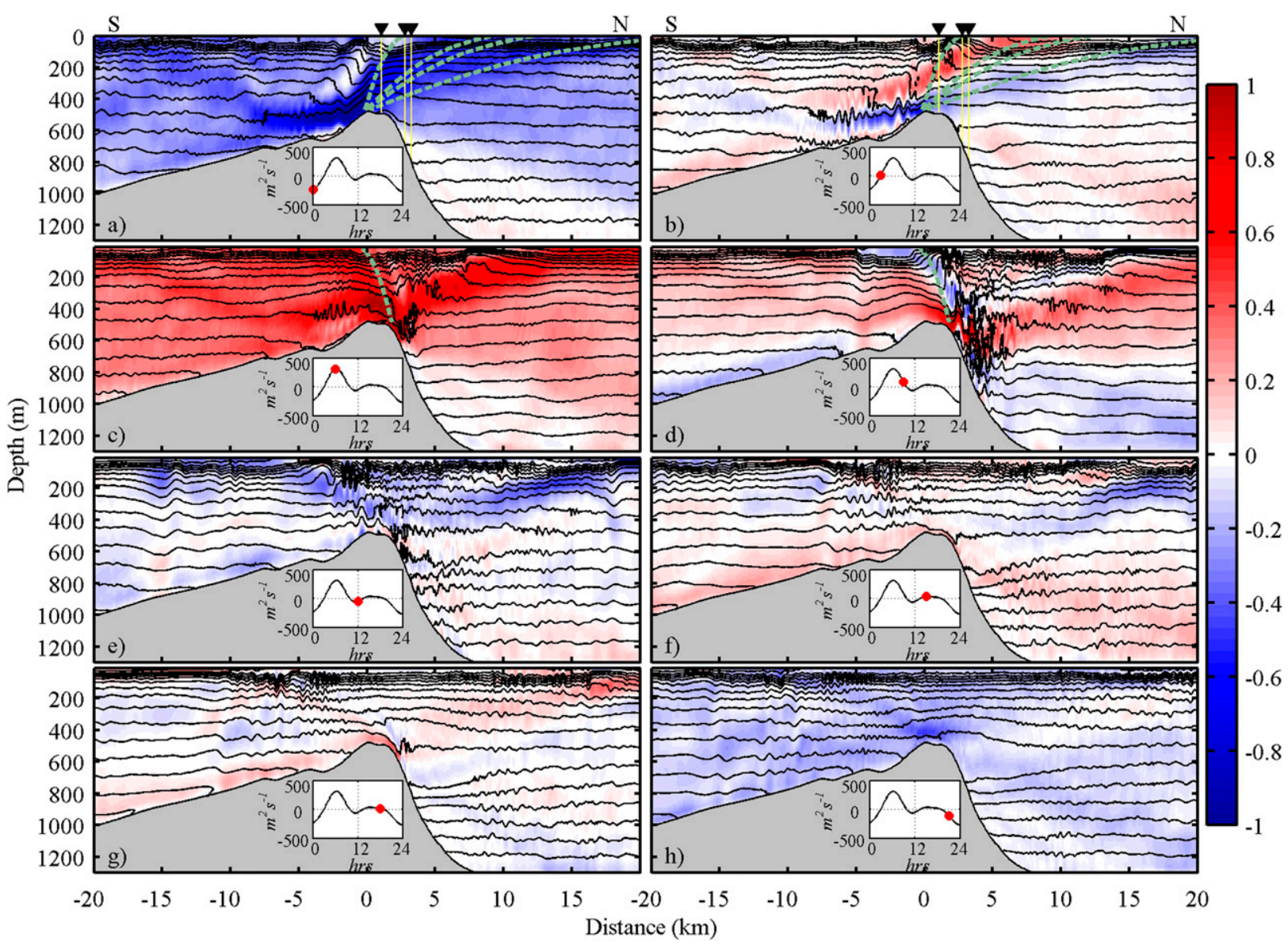

FIG. 6. Snapshots of simulated velocity (color) and isopycnals (contoured, interval $0.15 \mathrm{~kg} \mathrm{~m}^{-3}$, range $1024-1027 \mathrm{~kg} \mathrm{~m}^{-3}$ ) over $24 \mathrm{~h}$. Mooring and station locations $\mathrm{C} 1$ and $\mathrm{C} 2$ are indicated above (a) and (b) by small black triangles. Insets show modeled transport time series $\left(\mathrm{m}^{2} \mathrm{~s}^{-1}\right)$, and red dots indicate the time of each snapshot after hour 74 of the simulation. Characteristics for the D2, D3, D4, and the steady lee-wave response are shown in (a) and (b) (in increasing steepness). (c),(d) Characteristics for only the steady lee-wave response are shown.

and $6 \mathrm{~b}$ (in increasing steepness). They are calculated from the dispersion relation for internal waves (Gill 1982):

$$
\text { characteristic slope }{ }^{2}=\frac{k^{2}}{m^{2}}=\frac{\omega^{2}-f^{2}}{N(z)^{2}-\omega^{2}},
$$

where $\omega$ is the specified wave frequency, $f$ is the Coriolis frequency, and $k$ and $m$ are the horizontal and vertical wavenumbers of the wave. The steepest curves in Fig. 6 correspond to steady lee waves at peak cross-ridge flow. As these waves are steady they have zero Eulerian frequency and an intrinsic (Lagrangian) frequency that is set by the rate at which fluid parcels encounter the ridge crest (Klymak et al. 2010b):

$$
\omega_{\text {lee }}=U_{c} k_{\text {topo }} .
$$

The variable $k_{\text {topo }}$ is the characteristic wavenumber of the topography at a depth of $\delta=N / U_{0}$ below the crest, which we have estimated to be $4 \mathrm{~km} ; U_{c}$ is the peak tidal speed at the ridge crest, which takes values of $0.65 \mathrm{~m} \mathrm{~s}^{-1}$ for northward flow and $0.56 \mathrm{~m} \mathrm{~s}^{-1}$ for southward flow (Fig. 2), giving intrinsic wave periods of $1.7 \mathrm{~h}$ on the northern flank and $2.0 \mathrm{~h}$ on the southern flank during peak flow.

As the slope of the tidal lee wave changes with the advecting velocity $U_{c}$, and hence with the phase of the tide, it demonstrates poor alignment with any single wave characteristic most of the time. Closest agreement occurs during peak northward flow in Fig. 6c, when the tidal lee wave is well approximated by the steady leewave characteristic; however, we do not see such good agreement on the southern flank during peak southward flow. Bell (1975) demonstrates that advection by the barotropic tide causes long excursion length tidal flows to generate internal waves at both fundamental and higher harmonic frequencies and that it is the superposition of these waves that results in the tidal lee 
wave: a beamlike feature whose slope changes as the tide progresses and the composite frequencies disperse.

In this simulation there are two dominant frequencies in the background tide $\left(\mathrm{M}_{2}\right.$ and $\left.\mathrm{K}_{1}\right)$, each of which generates a response at its fundamental and harmonic frequencies (the $\mathrm{K}_{1}$ baroclinic response at this latitude is evanescent and fundamentally different from that at $\mathrm{M}_{2}$ ). It is the constructive superposition and subsequent dispersion of each of these frequency components that determines the time-dependent dynamics of the tidal lee wave. At slack tide the baroclinic structure of the tidal lee wave is visible (Figs. $6 \mathrm{~b}$ and $6 \mathrm{~d}$ ) before it is advected northward across the ridge crest (Fig. 6c). Similar features can be found in the SADCP transects (Figs. 3a,b). Isopycnals in the beam exhibit vertical displacements that are comparable to the horizontal width of the beam, and nonlinear steepening causes them to become convectively unstable (Fig. 6b).

Advection of the tidal lee wave past stations $\mathrm{C} 1$ and $\mathrm{C} 2$ forms the observed turbulent flow reversals, progressing from the surface to depth as a northward barotropic flow is established. Elevated turbulent dissipation rates of up to $0.03 \mathrm{~W} \mathrm{~m}^{-3}$ arising from convective overturning in this structure are identifiable in the station time series between 0200 and 0800 UTC 15 November 2012 at station $\mathrm{C} 1$, and between 0200 and 0800 UTC 17 November 2012 at station C2 (Fig. 5d). At the mooring in the center of the channel, each tide reversal forms a slanted turbulent structure in the time series that starts at the surface and extends downward in time (Fig. 4c). Unlike the CTD stations on the northern flank that only capture the tidal lee wave formed on the southern flank, the mooring captures turbulence associated with both northward- and southward-radiating tidal lee waves. Depth-integrated dissipation rates show maxima around $3 \mathrm{~h}$ after peak tidal flow (Fig. 4d). Though the mooring was approximately at the center of the channel, south to north tide reversals are not the same as north to south. A comparison of Figs. 6a and 6c shows that differences in both the slopes on the northern and southern flanks of the ridge, and the magnitudes of the northward and southward transports, influence the structure of the tidal lee wave at peak flow. The lee wave formed on the northern flank of the ridge is steeper than that on the south due to both steeper topography and relatively stronger northward flows.

As the surface tide becomes northward, the tidal lee wave formed on the southern flank advects to the north of the crest. Concurrently, the frequency constituents forming the lee wave disperse and the dominant feature that radiates into the far field has a slope that corresponds much more closely to an $\mathrm{M}_{2}$ ray path (Fig. $6 \mathrm{~d}$, between 25 and $35 \mathrm{~km}$ and shallower than $800 \mathrm{~m}$ ).
Comparison of Figs. $6 \mathrm{~d}$ and $6 \mathrm{~b}$ shows downward phase propagation (northward flow progresses from the top to the bottom of the beam, also see the supplementary animation), consistent with upward energy radiation by the radiating components of the baroclinic response.

A tidal lee wave forms on the northern flank of the ridge during northward flow where the large barotropic transport and steep bathymetric slope cause the lee wave to have a maximum steepness close to the steady lee-wave limit (green dashed line, Fig. 6c). By Fig. 6d, the frequency constituents making up the lee wave have begun to disperse, owing to their different phase speeds, and the slope is visibly reduced. In the time series from station $\mathrm{C} 2$, the turbulence arising from the southward radiating beam is characterized by its occurrence above the fast bottom jet, between 0800 and 1300 UTC 16 November 2012 and 0800 and 1200 UTC 17 November 2012 (Fig. 5b). As was the case during southward tide, these isopycnals steepen and break as the tide progresses, leading to mixing by Fig. $6 \mathrm{~d}$.

The deepest lobe of the tidal lee wave forms a strongly accelerated jet around $200 \mathrm{~m}$ thick at the crest of the ridge (Fig. 6c). The jet separates downstream of the ridge crest at $\sim 600 \mathrm{~m}$ in Fig. $6 \mathrm{c}$, shallowing to $\sim 500 \mathrm{~m}$ by Fig. $6 \mathrm{~d}$. The region around the separated jet is the site of significant overturning, formed by the transition of the jet from supercritical to subcritical in a hydraulic jump. An assessment of the layer Froude number of the jet can be made by analogy to a discretely layered fluid, wherein the layer is supercritical if the phase speed of interfacial waves is less than the speed of the fluid in the layer (Winters and Armi 2013). Using approximate values from the SADCP transects (Fig. 3) for layer thickness $(l=250 \mathrm{~m})$, and mooring for a mean layer speed $(\bar{U}=$ $\left.1.2 \mathrm{~m} \mathrm{~s}^{-1}\right)$ and mean layer stratification $(N=3 \mathrm{cph})$, we estimate the crest layer Froude number $\mathrm{Fr}_{l}$ of the jet to be $\sim 0.9$, supporting the idea that the jet is hydraulically controlled. The turbulence that arises in the hydraulic jump downstream is distinguished from that in the tidal lee wave, occurring as a direct result of the hydraulic control of the jet at the crest of the topography, rather than from the nonlinear steepening of the tidal lee wave. In contrast with the flows associated with the southwardradiating beam, flows downstream of the separation point have positive vertical shear resulting in the generation of clockwise rotating vortices or forward breaking. This turbulence is identifiable in the station data at depths below $500 \mathrm{~m}$, where it persists for up to $6 \mathrm{~h}$ past peak northward from 1000 to 1400 UTC 15 November at station $\mathrm{C} 1$ and at $\mathrm{C} 2$ from 1200 to 1800 UTC 16 November (Fig. 5d).

The key features described in this section are summarized in Fig. 7, which shows the baroclinic across-ridge 


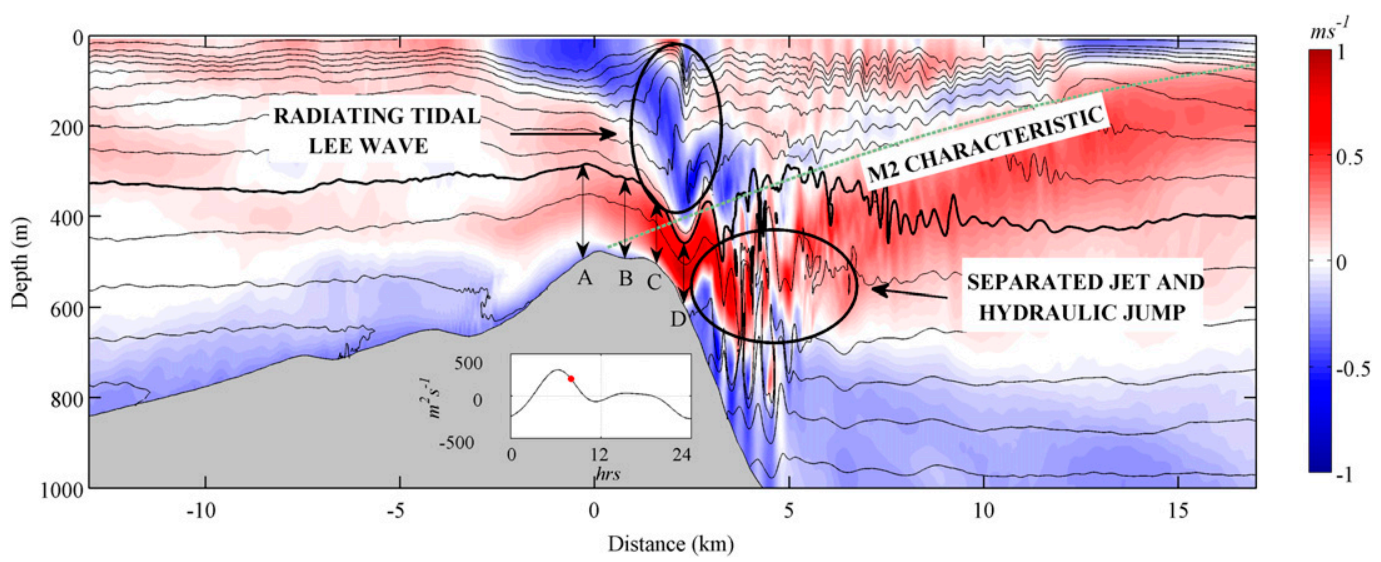

FIG. 7. The generation of tidal lee waves, internal tides, and hydraulic jumps at the ridge crest. Color is baroclinic across-ridge velocity (with the depth-mean northward flow removed), and black contours are isopycnals (as Fig. 6). The thicker isopycnal defines the hydraulically controlled layer, with layer Froude numbers $\mathrm{A}: \mathrm{Fr}_{l}=0.8$; $\mathrm{B}: \mathrm{Fr}_{l}=$ 1.0; $\mathrm{C}: \mathrm{Fr}_{l}=1.5$; and $\mathrm{D}: \mathrm{Fr}_{l}=1.1$, indicating a subcritical to supercritical transition at the crest.

velocity just after peak flow (a time between Figs. $6 \mathrm{c}$ and $6 \mathrm{~d})$. With the depth-mean velocity removed, the baroclinic structure of the response is clear and shows a steep internal wave beam corresponding to a southwardradiating tidal lee wave on the northern flank of the ridge. Energy radiating northward along an $\mathrm{M}_{2}$ characteristic remains from a similar steep tidal lee wave on the southern flank, whose frequency constituents have since dispersed or dissipated, leaving only the most energetic $\mathrm{M}_{2}$ characteristic clearly visible. We indicate the top of the hydraulically controlled layer with a bold contour in Fig. 7 and assess the Froude number by calculating the mean velocity and stratification in the layer. The jet is subcritical upstream of the crest $\left(\mathrm{A}: \mathrm{Fr}_{l}=0.8\right)$, critical at $\mathrm{B}\left(\mathrm{Fr}_{l}=\right.$ 1.0), and supercritical downstream (C: $\mathrm{Fr}_{l}=1.5$; $\mathrm{D}: \mathrm{Fr}_{l}=$ 2.1). There is some ambiguity in the definition of the jet, but the general result of a subcritical to supercritical transition is robust even if we use different criteria (e.g., defining the jet where the baroclinic speed is northward or where the speed is greater than the depth-mean speed). The hydraulically controlled northward bottom jet is associated with a hydraulic jump and dissipation where it separates from topography.

Time series of depth-integrated dissipation rates from stations $\mathrm{C} 1$ and $\mathrm{C} 2$ indicate that peak dissipation rates are associated with breaking and turbulence above the strong bottom current just after peak flow (Fig. 5d). This turbulence arises both from the hydraulic jump and the direct breaking of the southward-radiating tidal lee wave. At the mooring, however, peak dissipation rates are associated with the passage of breaking tidal lee waves (slanted structures in time series; Fig. 4c), as the turbulence associated with the hydraulic jump, though observed at the mooring, has decayed since its inception on the flanks.
Simulated flow during the weak beat of the tide exhibits poorer agreement with the observations, as it is during this time that three-dimensional effects dominate the characteristics of the flow (Figs. 6e-h). This phase of the tide is dealt with more completely in M16b, and we do not discuss it further here.

\section{b. Modeled time-mean spatial structure of turbulent dissipation rate at the ridge crest}

While the generation of turbulence by the hydraulic jump occurs just after peak tidal flow on the flanks of the ridge, turbulence generation by the breaking tidal lee wave occurs higher in the water column, reaching almost to the surface at station C2 (Fig. 5d). Observed timemean dissipation rates at station $\mathrm{C} 1$ and the first $24 \mathrm{~h}$ of station $\mathrm{C} 2$ are 0.64 and $2.8 \mathrm{~W} \mathrm{~m}^{-2}$, while concurrent dissipation rates at the mooring are 1.8 and $2.6 \mathrm{~W} \mathrm{~m}^{-2}$. A comparison of $\mathrm{C} 1$ and $\mathrm{C} 2$ normalized by the simultaneous dissipation rates at the mooring indicates that there is around 3 times more dissipation at $\mathrm{C} 2$ compared to $\mathrm{C} 1$, even when the change in the dissipation measured at the mooring during each of the stations is accounted for. Stations $\mathrm{C} 1$ and $\mathrm{C} 2$ are approximately $1 \mathrm{~km}$ apart, indicating strong gradients in the time-averaged dissipation rate close to the ridge crest.

Maps of time-averaged model dissipation rates (averaging over $5 \mathrm{~h}$ following peak flow) are presented in Fig. 8 and show reasonable agreement with observations in both their spatial distribution and order of magnitude. Some numerical noise appears as the dissipation rate involves second derivatives of the prognostic fields. Elevated dissipation rates are present throughout the water column around the ridge crest. At shallow depths the turbulence is driven by breaking in the tidal lee wave, while at depth on the flanks of the ridge the turbulence 


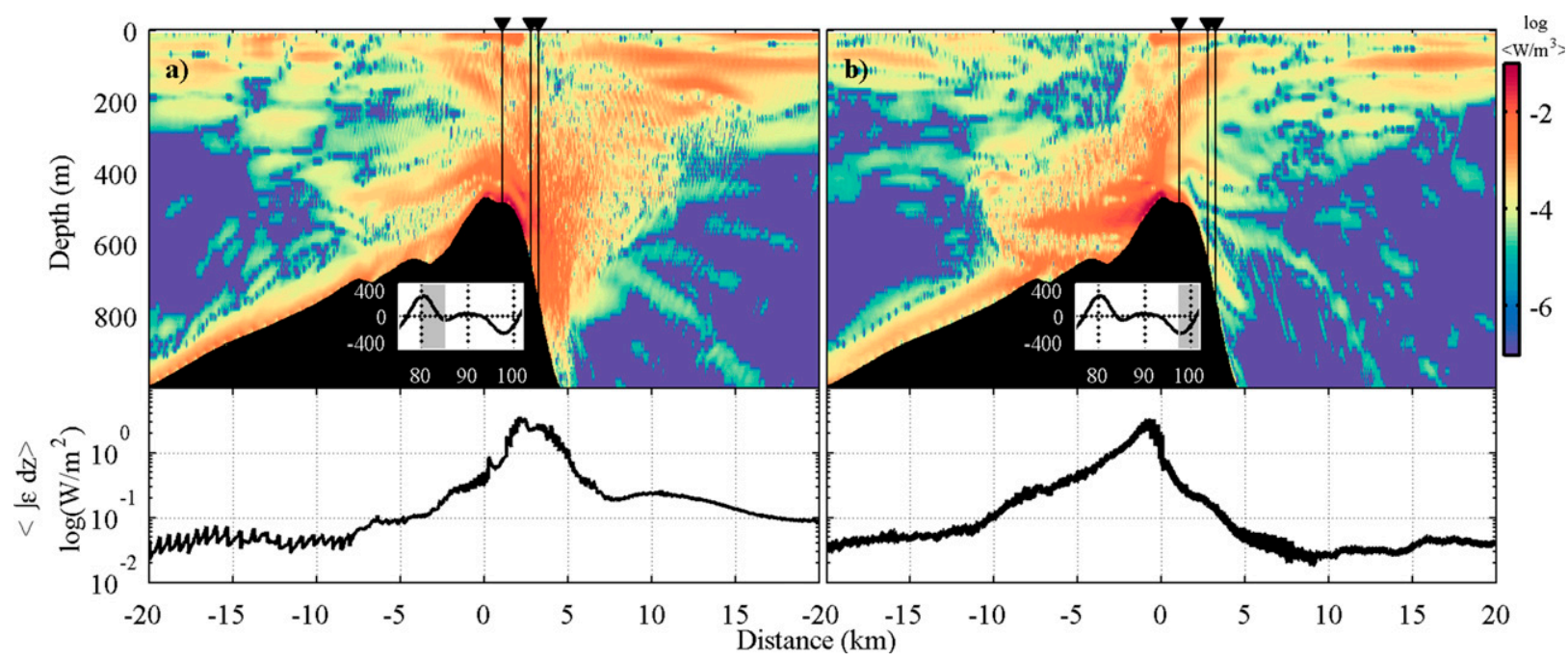

FIG. 8. Maps of 5-h averages of modeled dissipation rate at the ridge crest just after peak (a) northward and (b) southward flow. Insets show barotropic transport time series ( $\mathrm{m} \mathrm{s}^{-1}$ vs model hour); shaded region indicates averaging interval. Triangles and black lines indicate locations of mooring, station $\mathrm{C} 1$, and station $\mathrm{C} 2$. (bottom) Depth-integrated dissipation rates.

arises mainly from transient internal hydraulic jumps downstream of jet separation. Depth-integrated, timeaveraged dissipation rates show peaks on the flanks of the ridge, approximately at the location of station $\mathrm{C} 2$, where both processes contribute to the total turbulent dissipation. Depth-integrated dissipation rates averaged over the full $24 \mathrm{~h}$ (not shown) have two peaks, one on each flank, with reduced depth-integrated dissipation rates at the crest. Integrating the 24-h mean dissipation rate within $\pm 10 \mathrm{~km}$ of the ridge crest gives a total, tidally averaged dissipation rate over the ridge of $6 \mathrm{~kW} \mathrm{~m}^{-1}$. For comparison, AL03 estimate a dissipation rate of $0.1 \mathrm{~kW} \mathrm{~m}^{-1}$ for the section of ridge that they examined in the open ocean (see Fig. 1c), an order of magnitude smaller than that measured at our coastal channel site. The relative energetics of the two sites will be discussed in section $4 \mathrm{~d}$.

\section{c. Frequency constituents at the crest}

Bell (1975) predicts the generation of internal waves at tidal harmonics for long excursion length flows, and we identify these in power spectra of inferred vertical velocities at the $1-\mathrm{Hz}$ temperature loggers on the mooring (Fig. 9). The computation of spectra on an isopycnal, rather than in a fixed-depth coordinate system, reduces the impact of finestructure contamination arising from the vertical advection of a stepped temperature profile past the sensors (Phillips 1971). The mean densities observed by each sensor over the course of the deployment were used to form a set of reference isopycnals, whose vertical displacement was computed for all times. Small density inversions were occasionally present between sensors, and these were removed before calculating isopycnal depth by linearly interpolating over adjacent sensors. The vertical velocity is the time derivative of isopycnal depth, under the assumption that the contribution to the time derivative from the horizontal advection of features past the sensors was relatively small. The drifting of isopycnals into and out of the range of the mooring meant that some of the highest and lowest displacement records contain too many gaps to be used to compute spectra. However, a nearly continuous record was obtained for isopycnals at intermediate depths, and it is these that are used to compute the spectra shown in Fig. 9.

Spectra were computed for each isopycnal in five overlapping 4-day records that were then averaged to produce a single-frequency spectrum. Pairs of adjacent isopycnals were averaged together to form seven spectra associated with a range of mean isopycnal depths observed at the mooring. Peaks are present at all depths at $1-4 \mathrm{cpd}$ but are increasingly significant away from the surface, with harmonics at 3 and 4 cpd dominating the spectrum. Though some of this variance is likely to have arisen from the kinematic effect of advecting the wavefield past a fixed sensor, the strong signal suggests a contribution from free waves at these frequencies. The depth structure of each of these frequencies is explicitly shown in Fig. 9b. The subinertial D1 constituent contributes to the velocity and displacement variance at depth but decays rapidly away from the bottom, consistent with a subinertial, bottom-trapped wave response. Superinertial frequencies D2, D3, and D4 have variance distributed throughout the water column, consistent 

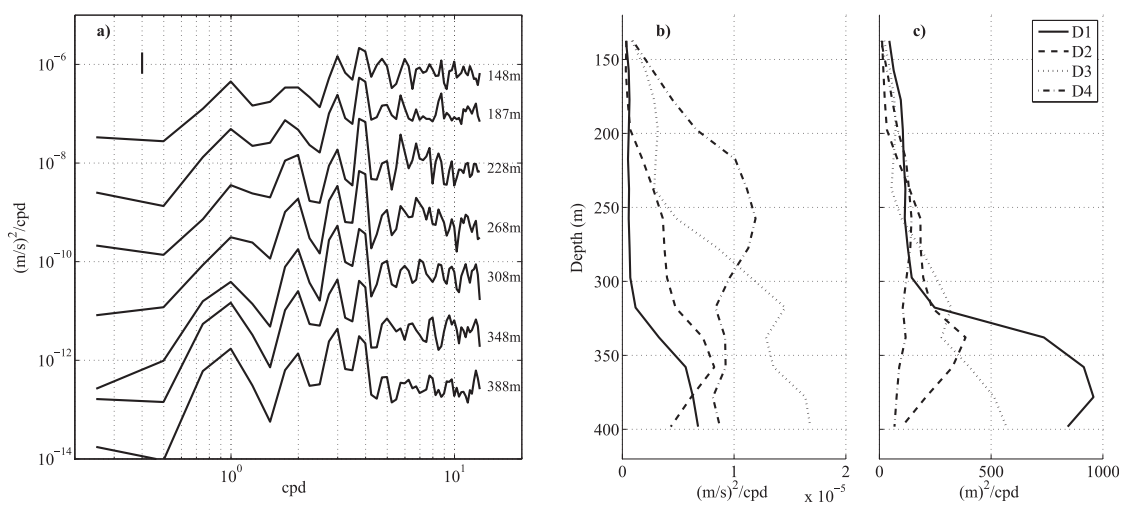

FIG. 9. (a) Power spectra of vertical velocities on isopycnals inferred from thermistor records on mooring in center channel. Spectra are offset by $0.08\left(\mathrm{~m} \mathrm{~s}^{-1}\right)^{2} \mathrm{cpd}^{-1}$ for each depth, with mean isopycnal depths shown. The $95 \%$ confidence level is shown in the upper-left corner. (b) Amplitudes of diurnal (D1), semidiurnal (D2), and harmonics (D3 and D4) as a function of mean isopycnal depth. (c) As in (b), but for displacements rather than vertical velocities.

with a radiating response. Peaks are present in $\mathrm{D} 3$ below $250 \mathrm{~m}$ and D4 above $300 \mathrm{~m}$. Displacement spectra (not shown) are redder, as the Fourier amplitudes of displacement and vertical velocity are related by frequency. However, prominent harmonics are still present, with most displacement energy in D1 and D3 at depth (Fig. 9c). Modeled spectra (not shown) have qualitatively similar features, with significant peaks at D3 and D4.

\section{d. The radiated wavefield: Energetics and frequency constituents}

To assess the amount of energy at the harmonics of the forced frequencies in the far field, we evaluate the flux of baroclinic wave energy at the forced and harmonic frequencies at $-20 \mathrm{~km}$ (south) and $20 \mathrm{~km}$ (north) in the model, during the final $25 \mathrm{~h}$ of the simulation. Baroclinic flux is defined as

$$
F=\frac{1}{T} \int_{0}^{T} \int_{0}^{h} p^{\prime} u^{\prime} d z
$$

where $u$ is the along-channel velocity, $p$ is the pressure, $T$ is the period of the tidal constituent, and $h$ is the depth ocean. Primes indicate that the depth-mean and timemean components of the fields have been removed (cf. Nash et al. 2005). In an Eulerian time series such as that obtained by a mooring or CTD station, the generation of kinematic harmonics from the advection of a wavefield past a fixed sensor are extremely difficult to correct for; however, in a model it is possible to estimate the influence of this advection on the computed fluxes. As such, we compute wave fluxes measured both in an Eulerian frame (equivalent to a fixed mooring) and a Lagrangian frame, advected by the background tide and consequently capturing only the dynamic effects arising from freely propagating internal waves. The harmonic components of the time series in each frame of reference are computed by a least squares fit for amplitude and phase to a sum of sinusoids at frequencies corresponding to D1, D2, D3, D4, and D5.

Despite strong advective velocities $\left(0.2-0.3 \mathrm{~m} \mathrm{~s}^{-1}\right)$, there is negligible difference between the fluxes computed in either frame of reference, indicating that the presence of spurious harmonics in the time series is small. As a result, we present only the fluxes calculated in an Eulerian frame of reference (Fig. 10). Harmonics (D3, D4, and D5) account for up to $30 \%$ of the generated flux to the north of the ridge and $10 \%$ of the flux to the south. Given the high dissipation rates close to the ridge crest, these harmonic flux fractions likely represent a lower bound on harmonic energy content closer to the crest, as the higher-frequency waves have relatively smaller length scales are preferentially dissipated. Total fluxes in each frame are similar, with a net northward flux of $13 \mathrm{~kW} \mathrm{~m}^{-1}$ and southward flux of $2.6 \mathrm{~kW} \mathrm{~m}^{-1}$, comparable to AL03, who measure an outgoing flux of

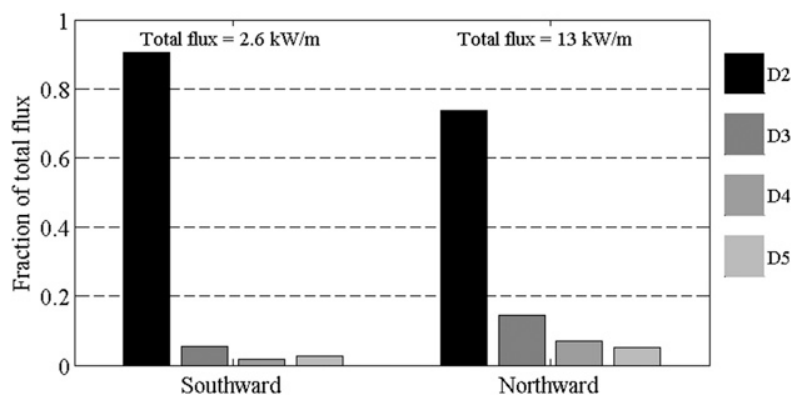

FIG. 10. Modeled fluxes at D2 and harmonic frequencies at $x=-20 \mathrm{~km}$ (southward) and $x=20 \mathrm{~km}$ (northward). 
$7 \mathrm{~kW} \mathrm{~m}^{-1}$ much farther west along the ridge, in the open ocean (see Fig. 1a). At our coastal location, the barotropic tide has a larger amplitude than in the open ocean, and this may account for the relatively larger fluxes that we estimate compared to AL03. Nevertheless, our calculations support the conclusions of AL03 that the Mendocino Ridge is an important source of internal tide energy in the northeastern Pacific.

From our model results we infer a near-ridge dissipation rate of $6 \mathrm{~kW} \mathrm{~m}^{-1}$, and a total outgoing flux of $15.6 \mathrm{~kW} \mathrm{~m}^{-1}$. If we assume steady-state dynamics, the conversion of energy from barotropic to baroclinic motions (including all frequency constituents), $C$ is given by (Kang and Fringer 2012)

$$
C-\nabla \cdot \mathbf{F}=\epsilon,
$$

where $\epsilon$ is the dissipation rate of the baroclinic energy and $\mathbf{F}$ is the vector flux. As such, we infer a nearridge conversion of $21.6 \mathrm{~kW} \mathrm{~m}^{-1}$ into baroclinic energy. Buijsman et al. (2012) define the local dissipation efficiency $q$ as the fraction of energy extracted from the barotropic tide that is dissipated locally, and from our simulation we infer

$$
q=\text { local dissipation/conversion }=28 \% .
$$

In contrast, AL03 infer a near-ridge dissipation rate of $0.1 \mathrm{~kW} \mathrm{~m}^{-1}$ using a finescale parameterization and a total outgoing flux of $7 \mathrm{~kW} \mathrm{~m}^{-1}$ at their deep-ocean site, giving $q=1 \%$. Notwithstanding the differences in the methods used in each study, the large difference in $q$ at the two locations along the ridge suggests the importance of regional factors in determining local energy budgets. At our coastal location, not only is the barotropic tide stronger than in the deep ocean, but the trapped subinertial tidal constituent strongly affects the dynamics of our observed flow. As this constituent cannot radiate away from topography, it contributes to near-field mixing without contributing to the outgoing flux, giving a much higher local dissipation efficiency than at a location where there are no trapped tides or where the trapped component may be much less energetic (M16b). It is these types of processes that complicate attempts to parameterize near-field tidal dissipation, and this will be discussed in the next section.

\section{A general relation between turbulent dissipation rate and tidal flow speed}

One of the earliest attempts to parameterize tidal dissipation in the ocean was by Taylor (1919), who assumed the energy was dissipated in a turbulent bottom boundary layer that exerts a quadratic bottom drag on the flow. In this case the dissipation of tidal energy is proportional to the cube of the barotropic tidal speed, with a fixed drag coefficient. This parameterization is appropriate for shallow seas; however, in the abyssal ocean dissipation of the barotropic tide is strongly enhanced over regions of rough topography (Egbert and Ray 2000) and is thought to be driven both by internal wave generation and the type of near-topographic turbulence described in this paper. Klymak et al. (2010a) provide a parameterization for the amount of energy dissipated directly to turbulence close to tall topography, wherein, like Taylor (1919),

$$
D \propto U_{0}^{3},
$$

where $D$ is the total near-topographic dissipation rate averaged over one tidal cycle, and $U_{0}$ is the tidal amplitude of the tide in the deep ocean away from topography. In this parameterization, the drag coefficient is variable, depending on parameters including bathymetric height, stratification, and tidal frequency. Motivated by this prediction, we use our 12-day time series from the mooring to assess the relationship between the depth-mean flow speed $U_{c}$ and depth-integrated dissipation rate $\varepsilon$ at the center of the channel. Crosscorrelating hourly averages of depth-mean flow speed and dissipation rate shows a peak in correlation when the dissipation time series lags the flow speed by $3 \mathrm{~h}$, as such we lag the dissipation rate time series before performing the fits. We then compute 24-h averages of $U_{c}$ and $\varepsilon$, giving us a total of 11 data points corresponding to each day that the mooring was deployed, as the tide transitioned from spring to neap. Because of the knockdown of the mooring during periods of strong current, flow speeds $U_{c}$ were calculated as depth means below $250 \mathrm{~m}$. Depth-integrated dissipation rates $\varepsilon$ are computed from all instruments, though computing a depth mean below $250 \mathrm{~m}$ makes no noticeable difference to the fits shown. The data points and a linear least squares fit are shown in Fig. 11 (blue points and line). The fit is performed using the logarithm of the dissipation rates and flow speeds to a linear model with the slope as a free parameter. For 24-h averages, we find that the dissipation rate is proportional to $U_{c}^{2}$, with $60 \%$ of the variance being explained by the model. We note that this $R^{2}$ is only just significant at the $95 \%$ level with a sample size of 11 points. Performing a similar analysis but instead using the 24-h peak flow speeds, rather than time mean, causes the slope to be reduced to $U_{c}^{1.6}$, with the variance explained increasing to $80 \%$ (black points and line, Fig. 11).

Several factors make the application of Klymak et al. (2010a) to this dataset uncertain, perhaps the most important relating to the spatial distribution of time-averaged 


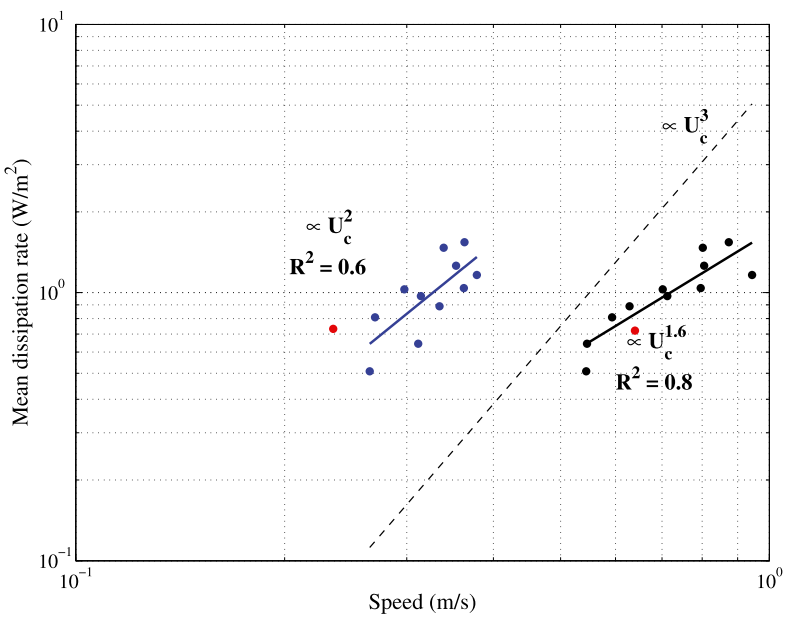

FIG. 11. The 24-h mean (blue) and peak speed (black) vs 24-h mean depth integrated dissipation rate lagged by $3 \mathrm{~h}$. Fitted slopes show a power-law relation of 2 and 1.6. Dashed line shows $D \propto U_{c}^{3}$. Modeled mean dissipation rate and speeds at the channel are shown in red.

turbulence at the crest of the ridge. If, in a time average, the measured dissipation rate at the mooring is not linearly proportional to the total near-field dissipation rate, then it is plausible to expect a systematic bias in the comparison of dissipation rate versus flow speed. Modeled dissipation rates show that the depth-integrated dissipation rate is not constant across the ridge (Fig. 8), and it seems likely that the spatial distribution of the turbulence may change as the tidal amplitude varies through the spring-neap cycle. Additional uncertainties arise because we are unable to unambiguously identify $U_{0}$ in our observations and instead use $U_{c}$ and that our observations involve two dominant frequencies, while the parameterization was formulated for a single-frequency tide. The inherent nonlinearity of the response suggests that the dissipation should not be the sum of the dissipation of each constituent separately, and as such we have considered the tidal peak and average flow speeds of all constituents together in order to form these fits. Finally, these observations were obtained in a channel, where three-dimensional bathymetry strongly influences the flow. One such influence is the generation of trapped topographic waves by the subinertial $\left(\mathrm{K}_{1}\right)$ tidal component, which can become resonant at certain topographies and are responsible for bottom-enhanced $\mathrm{K}_{1}$ transports close to the ridge (Swart et al. (2011); M16b). Such phenomena are beyond the scope of a parameterization such as that proposed by Klymak et al. (2010a).

\section{Summary}

We observe energetic, time-dependent turbulence in a channel at the crest of the Mendocino Ridge, which we interpret with the aid of a high-resolution, 2.5dimensional numerical model. This site is highly turbulent because of the combination of small topographic Froude number with large excursion length. A strong diurnal inequality modulates turbulence, alternately enhancing and suppressing the generation of tidal lee waves.

The constructive superposition of trapped and radiating internal waves at both the forcing frequencies $\left(\mathrm{K}_{1}\right.$, subinertial at this latitude, and $\mathrm{M}_{2}$ ) and their harmonics create tidal lee waves: large-amplitude beamlike features that form during strong flow phases of the tide and are advected past the mooring and CTD stations as each strong tide relaxes, giving rise to striking flow patterns in the time series. From the model output we identify two different processes that generate turbulence in close vicinity of the ridge crest. The first is via steepening and convective instability within the beam of the tidal lee wave that generates turbulence above a bottomintensified, hydraulically controlled jet. The second is from the formation of a transient hydraulic jump on the lee side past the jet separation point. These processes are identified in the observed time series, where overturns associated with each process occur at different depths and times in conjunction with different velocity structures. In particular, turbulence associated with the tidal lee wave occurs above the crest of the topography reaching almost to the surface, while turbulence associated with the hydraulic jump occurs at depth on the flanks of the ridge. Modeled time-mean dissipation rates are of comparable magnitude to observations and illustrate the strong spatial variations in the distribution of breaking.

The importance of nonlinearity on determining the turbulence near the crest is illustrated by the alternating constructive and destructive superpositions of the $\mathrm{K}_{1}$ and $\mathrm{M}_{2}$ baroclinic responses. The generation of a tidal lee wave leads to large dissipation rates when the constituents are in phase, in strong contrast to the negligible dissipation on alternate phases when the constituent flows are opposed and no tidal lee wave forms. Large excursion lengths in the channel lead to the formation of internal waves at harmonics of the forcing frequencies, and the model predicts that they may compose more than $30 \%$ of wave energy generated at the northern flank of the ridge.

Using the model to infer the radiating internal tide flux and total dissipation rate close to the crest, we have estimated that the local dissipation efficiency is large at $q=28 \%$ in the vicinity of our channel. Small-scale features such as channels such as this may have a disproportionate influence on tidally driven mixing close to topography, as large excursion lengths generate strongly nonlinear and dissipative features. 
Acknowledgments. Ship time was provided through the UC Ship Funds program. Shaun Johnston, Uwe Send, and Janet Sprintall generously loaned instrumentation. At sea help with SADCP data processing was provided by Jules Hummon. The authors thank Capt. Dave Murline and the crew on the R/V Melville. Field work was greatly aided by the hard work of Paul Chua and 10 UNOLS volunteers, who worked cheerfully and tirelessly to obtain this dataset. RCM thanks Bill Young for useful conversations in relation to this work. RCM is funded by the Office of Naval Research under Grant ONR N0001412-1-0943 and by the National Science Foundation under Grant NSF OCE 1129763. We thank Louis Gostiaux and two anonymous reviewers for their comments that have improved this work.

\section{REFERENCES}

Abe, S., and T. Nakamura, 2013: Processes of breaking of largeamplitude unsteady lee waves leading to turbulence. J. Geophys. Res. Oceans, 118, 316-331, doi:10.1029/2012JC008160.

Alford, M. H., 2010: Sustained, full-water-column observations of internal waves and mixing near Mendocino Escarpment. J. Phys. Oceanogr., 40, 2643-2660, doi:10.1175/2010JPO4502.1.

— Strait: Two tales of two ridges. J. Phys. Oceanogr., 41, 22112222, doi:10.1175/JPO-D-11-073.1.

Althaus, A., E. Kunze, and T. B. Sanford, 2003: Internal tide radiation from Mendocino Escarpment. J. Phys. Oceanogr., 33, 1510-1527, doi:10.1175/1520-0485(2003)033<1510: ITRFME $>2.0 . \mathrm{CO} ; 2$.

Baines, P. G., and K. Hoinka, 1985: Stratified flow over twodimensional topography in fluid of infinite depth: A laboratory simulation. J. Atmos. Sci., 42, 1614-1630, doi:10.1175/ 1520-0469(1985)042<1614:SFOTDT $>2.0 . C O ; 2$.

Bell, T. H., 1975: Lee waves in stratified flows with simple harmonic time dependence. J. Fluid Mech., 67, 705-722, doi:10.1017/ S0022112075000560.

Buijsman, M. C., S. Legg, and J. Klymak, 2012: Double-ridge internal tide interference and its effect on dissipation in Luzon Strait. J. Phys. Oceanogr., 42, 1337-1356, doi:10.1175/JPO-D-11-0210.1.

Daru, V., and C. Tenaud, 2004: High order one-step monotonicitypreserving schemes for unsteady compressible flow calculations. J. Comput. Phys., 193, 563-594, doi:10.1016/j.jcp.2003.08.023.

Dewey, R. K., 1999: Mooring design \& dynamics-A MATLAB package for designing and analyzing oceanographic moorings. Mar. Models, 1, 103-157, doi:10.1016/S1369-9350(00)00002-X.

Dillon, T., 1982: Vertical overturns: A comparison of Thorpe and Ozmidov length scales. J. Geophys. Res., 87, 9601-9613, doi:10.1029/JC087iC12p09601.

Di Lorenzo, E., W. R. Young, and S. G. Llewellyn Smith, 2006: Numerical and analytical estimates of $\mathrm{M}_{2}$ tidal conversion at steep oceanic ridges. J. Phys. Oceanogr., 36, 1072-1084, doi:10.1175/JPO2880.1.

Egbert, G., and R. D. Ray, 2000: Significant dissipation of tidal energy in the deep ocean inferred from satellite altimeter data. Nature, 405, 775-778, doi:10.1038/35015531.

- and S. Y. Erofeeva, 2002: Efficient inverse modeling of barotropic ocean tides. J. Atmos. Oceanic Technol., 19, 183-204, doi:10.1175/1520-0426(2002)019<0183:EIMOBO>2.0.CO;2.
Farmer, D. M., and J. D. Smith, 1980: Tidal interaction of stratified flow with a sill in Knight Inlet. Deep-Sea Res., 27A, 239-254, doi:10.1016/0198-0149(80)90015-1.

Galbraith, P. S., and D. E. Kelley, 1996: Identifying overturns in CTD profiles. J. Atmos. Oceanic Technol., 13, 688-702, doi:10.1175/1520-0426(1996)013<0688:IOICP>2.0.CO;2.

Gargett, A. E., and T. Garner, 2008: Determining Thorpe scales from ship-lowered CTD density profiles. J. Atmos. Oceanic Technol., 25, 1657-1670, doi:10.1175/2008JTECHO541.1.

Gill, A. E., 1982: Atmosphere-Ocean Dynamics. Academic Press, $662 \mathrm{pp}$.

Hasumi, H., and N. Suginohara, 1999: Effects of locally enhanced vertical diffusivity over rough bathymetry on the World Ocean circulation. J. Geophys. Res., 104, 23 367-23 374, doi:10.1029/ 1999JC900191.

Kang, D., and O. B. Fringer, 2012: Energetics of barotropic and baroclinic tides in the Monterey Bay area.J. Phys. Oceanogr., 42, 272-290, doi:10.1175/JPO-D-11-039.1.

Klymak, J., R. Pinkel, and L. Rainville, 2008: Direct breaking of the internal tide near topography: Kaena Ridge, Hawaii. J. Phys. Oceanogr., 38, 380-399, doi:10.1175/2007JPO3728.1.

_ , S. Legg, and R. Pinkel, 2010a: A simple parameterization of turbulent tidal mixing near supercritical topography. J. Phys. Oceanogr., 40, 2059-2074, doi:10.1175/2010JPO4396.1.

,$- \ldots$, and $—, 2010 \mathrm{~b}$ : High-mode stationary waves in stratified flow over large obstacles. J. Fluid Mech., 644, 321336, doi:10.1017/S0022112009992503.

Legg, S., and K. M. H. Huijts, 2006: Preliminary simulations of internal waves and mixing generated by finite amplitude tidal flow over isolated topography. Deep-Sea Res. II, 53, 140-156, doi:10.1016/j.dsr2.2005.09.014.

— turning generated by tidal flow over a tall steep ridge. J. Phys. Oceanogr., 38, 1949-1964, doi:10.1175/2008JPO3777.1.

Marshall, J., A. Adcroft, C. Hill, L. Perelman, and C. Heisey, 1997: A finite-volume, incompressible Navier Stokes model for studies of the ocean on parallel computers. J. Geophys. Res., 102, 5753-5766, doi:10.1029/96JC02775.

Melet, A., S. W. Venayagamoorthy, S. Legg, and K. L. Polzin, 2013: Sensitivity of the ocean state to the vertical distribution of internal-tide-driven mixing. J. Phys. Oceanogr., 43, 602-615, doi:10.1175/JPO-D-12-055.1.

Nakamura, T., Y. Isoda, H. Mitsudera, S. Takagi, and M. Nagasawa, 2010: Breaking of unsteady lee waves generated by diurnal tides. Geophys. Res. Lett., 37, L04602, doi:10.1029/2009GL041456.

Nash, J. D., M. H. Alford, and E. Kunze, 2005: On estimating internal-wave energy fluxes in the ocean. J. Atmos. Oceanic Technol., 22, 1551-1570, doi:10.1175/JTECH1784.1.

Osafune, S., and I. Yasuda, 2013: Remote impacts of the 18.6 year period modulation of localized tidal mixing in the North $\mathrm{Pa}$ cific. J. Geophys. Res. Oceans, 118, 3128-3137, doi:10.1002/ jgrc. 20230.

Osborn, T. R., and C. S. Cox, 1972: Oceanic fine structure. Geophys. Astrophys. Fluid Dyn., 3, 321-345, doi:10.1080/ 03091927208236085.

Phillips, O. M., 1971: On spectra measured in an undulating layered medium. J. Phys. Oceanogr., 1, 1-6, doi:10.1175/ 1520-0485(1971)001<0001:OSMIAU > 2.0.CO;2.

Rapaka, N. R., B. Gayen, and S. Sarkar, 2013: Tidal conversion and turbulence at a model ridge: Direct and large eddy simulations. J. Fluid Mech., 715, 181-209, doi:10.1017/jfm.2012.513.

Simmons, H. L., S. R. Jayne, L. C. St. Laurent, and A. J. Weaver, 2004: Tidally driven mixing in a numerical model of the ocean 
general circulation. Ocean Modell., 6, 245-263, doi:10.1016/ S1463-5003(03)00011-8.

Swart, N. C., S. E. Allen, and B. J. W. Greenan, 2011: Resonant amplification of subinertial tides in a submarine canyon. J. Geophys. Res., 116, C09001, doi:10.1029/ 2011JC006990.

Taylor, G. I., 1919: Tidal friction in the Irish Sea. Proc. Roy. Soc. London, A96, 330, doi:10.1098/rspa.1919.0059.

Thorpe, S. A., 1977: Turbulence and mixing in a Scottish Loch. Philos. Trans. Roy. Soc. London, A286, 125-181, doi:10.1098/ rsta.1977.0112.
Visbeck, M., 2002: Deep velocity profiling using lowered acoustic Doppler current profilers: Bottom track and inverse solutions. J. Atmos. Oceanic Technol., 19, 794-807, doi:10.1175/ 1520-0426(2002)019<0794:DVPULA > 2.0.CO;2.

Winters, K. B., and L. Armi, 2013: The response of a continuously stratified fluid to an oscillating flow past an obstacle. J. Fluid Mech., 727, 83-118, doi:10.1017/jfm.2013.247.

Zhang, Y., and J. N. Moum, 2010: Inertial-convective subrange estimates of thermal variance dissipation rate from moored temperature measurements. J. Atmos. Oceanic Technol., 27, 1950-1959, doi:10.1175/2010JTECHO746.1. 